\title{
Relating Structure and Dynamics in RNA Biology
}

\section{Kevin P. Larsen, ${ }^{1,2,4}$ Junhong Choi, ${ }^{1,3,4}$ Arjun Prabhakar, ${ }^{1,2}$ Elisabetta Viani Puglisi, ${ }^{1}$ and Joseph D. Puglisi ${ }^{1}$}

\author{
${ }^{1}$ Department of Structural Biology, Stanford University School of Medicine, Stanford, California 94305 \\ ${ }^{2}$ Biophysics Program, Stanford University, Stanford, California 94305 \\ ${ }^{3}$ Department of Applied Physics, Stanford University, Stanford, California 94305 \\ Correspondence: puglisi@stanford.edu; epuglisi@stanford.edu
}

\section{SUMMARY}

Recent advances in structural biology methods have enabled a surge in the number of RNA and RNA-protein assembly structures available at atomic or near-atomic resolution. These complexes are often trapped in discrete conformational states that exist along a mechanistic pathway. Single-molecule fluorescence methods provide temporal resolution to elucidate the dynamic mechanisms of processes involving complex RNA and RNA-protein assemblies, but interpretation of such data often requires previous structural knowledge. Here we highlight how single-molecule tools can directly complement structural approaches for two processestranslation and reverse transcription-to provide a dynamic view of molecular function.

\section{Outline}

1 Introduction

2 Structural dynamics of the ribosome during decoding

3 Modulation of translation decoding dynamics by $\mathrm{m}^{6} \mathrm{~A}$ mRNA modifications

4 Modulation of translation decoding dynamics by 2'-O-methylation

5 Next steps in studying the role of mRNA modification in translation decoding

6 Structural dynamics of HIV-1 reverse transcription initiation
7 HIV-1 viral RNA-tRNA ${ }^{\text {Lys }}{ }_{3}$ complex structure and heterogeneity

8 Interactions of HIV-1 RT with the primer-template complex

9 Insights into the tertiary structure of the HIV-1 RT initiation complex

10 Next steps in studying HIV-1 reverse transcription initiation

11 Concluding remarks

References

${ }^{4}$ These authors contributed equally to this work.

Editors: Thomas R. Cech, Joan A. Steitz, and John F. Atkins

Additional Perspectives on RNA Worlds available at www.cshperspectives.org 
K.P. Larsen et al.

\section{INTRODUCTION}

The past decades have seen an explosion in structures of RNA and RNA-protein assemblies, including the ribosome and spliceosome. These structures have revealed the basic molecular principles of RNA secondary and tertiary folding and recognition of RNAs by structured and unstructured protein domains. Yet these structures represent static snapshots of the dynamic RNA-protein machinery of the cell. What has been lacking are time-resolved methods to link detailed structural views into a mechanistic movie of biological systems. These systems evolve temporally in both macromolecular conformation and in chemical composition (ligands or factors bound) and may proceed along different mechanistic pathways. Single-molecule methods have provided a bridge between structure and dynamics, allowing real-time analysis of RNAs and their assemblies. Here we address the interplay of structure and dynamics, using examples from our recent work on translation by the ribosome and HIV reverse transcription.

The three major structural methods-X-ray crystallography, nuclear magnetic resonance (NMR) spectroscopy, and cryo-electron microscopy (cryo-EM)-provide different portals into dynamics (Fig. 1). X-ray crystallography

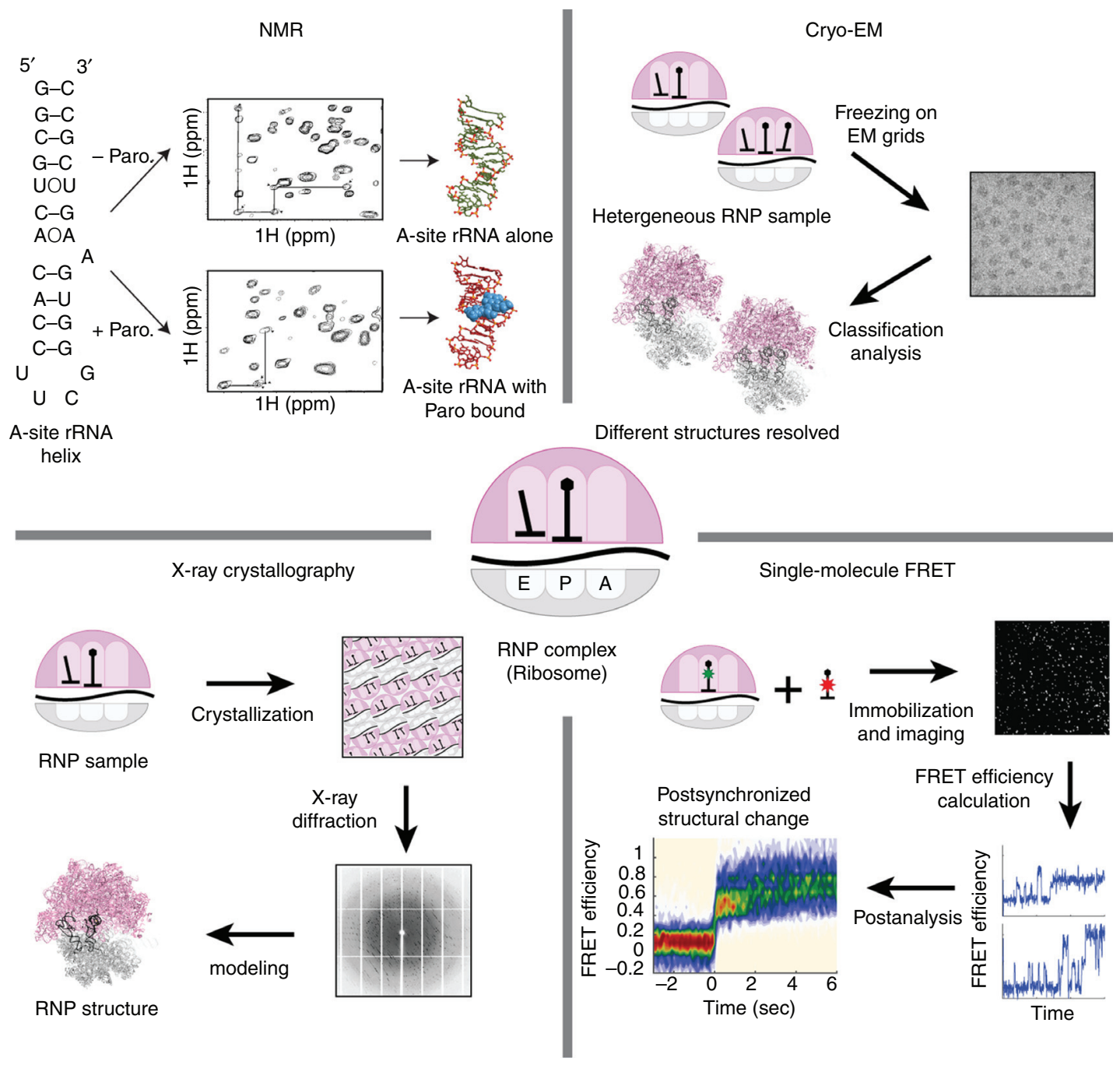

Figure 1. Major structural methods to study RNA-RNA-protein complexes. (Top left) Structures of ribosomal RNA (rRNA) helix with or without antibiotic paromomycin (Paro). (Adapted from Fourmy et al. 1998.) (Bottom left) High-resolution structure of ribosome using X-ray crystallography. (Top right) Cryo-electron microscopy (cryo-EM) structures of ribosome, with or without A-site transfer RNA (A-tRNA). (Bottom right) Single-molecule Förster resonance energy transfer (FRET) data showing binding of A-tRNA to the ribosome. (Data adapted from Fourmy et al. 1998 for nuclear magnetic resonance [NMR] spectroscopy [Protein Data Bank (PDB) IDs 1FYP, 1FYO], PDB ID 4V51 for X-ray crystallography, 5JTE for cryo-EM, and Choi et al. 2018 for single-molecule FRET.) 
requires crystallization of macromolecular complexes into regular lattices, which in certain cases can skew conformations because of intermolecular packing interactions. Data in X-ray diffraction are derived from coherent scattering of the X-ray beam by all members of the crystalline lattice. Dynamic information is often inferred from so-called B-factors, or "temperature factors," that reflect uncertainty in the location of atoms-high B-factors can result from dynamic regions in a macromolecule or from errors during modeling. Time-resolved conformational changes have been observed but require triggering of all members of the lattice simultaneously. Synchronizing conformational changes within the crystalline lattice often requires an external cue, typically light, to initiate a reaction (Srajer et al. 1996; Jung et al. 2013). Recent advances in the field of coherent X-ray sources (X-ray free-electron lasers or XFELs) have enabled faster data acquisition on nanocrystalline materials (Chapman et al. 2011; Tenboer et al. 2014). The fast data acquisition at room temperature is coupled with small crystal size to allow rapid mixing with ligands that can enter the crystal lattice. This has led to X-ray studies on conformational changes induced by ligands that bind to RNA (Stagno et al. 2017). Although still in its infancy and often restricted to specific cases, X-ray crystallography using XFELs shows potential for studying complex biomolecular dynamics.

NMR spectroscopy is a powerful probe of chemical dynamics, over a broad range of timescales and processes. NMR relaxation measurements can probe residue-byresidue motions on timescales of $10^{-9}$ to $10^{-5}$ sec to reveal fast movements within biomolecules. Advances in using relaxation dispersion methods have allowed investigation of "excited," lowly populated states for RNAs and proteins at intermediate timescales; the work of Al-Hashimi and coworkers in particular has shown how RNA can sample alternate pairings on a micro to millisecond range (AlHashimi 2013). NMR can also monitor slower processes $\left(10^{-3} \mathrm{sec}\right.$ and longer timescales) through distinctions in chemical shifts of resonances for different states (Zhou et al. 2016). However, NMR of RNAs, proteins, and their complexes suffer from size limitations on systems that can be investigated. As molecular weight increases, spectral complexity increases and resonances broaden because of slow molecular tumbling and efficient relaxation. These size limitations can be partially overcome by clever stable isotope-labeling strategies, novel NMR experiments that diminish relaxation mechanisms (like transverse relaxation optimized spectroscopy [TROSY]), or by solid state NMR.

Cryo-EM has undergone an impressive improvement allowing atomic resolution structures of many key RNAprotein complexes-ribosomes, spliceosomes, and RNA polymerase complexes among others (Bai et al. 2015; Cheng
2015; Yan et al. 2015; Robinson et al. 2016). Cryo-EM uses samples embedded in vitreous ice without additional staining, and imaging is performed using a low electron dose to avoid damage and preserve structural information. This results in images with low signal-to-noise ratio in which the contrast comes from the scattering of atoms in the biomolecules. RNA has an advantage compared with other biomolecules as high scattering is obtained from the phosphate backbone. Recent technological advances in both hardware and software have driven the improved resolution of cryoEM structures into the realm of 3-5 $\AA$ resolution: Using a direct electron detection camera with increased sensitivity, cryo-EM data are taken as movies with many sequential frames at a low dose ( $\mathrm{Li}$ et al. 2013). These frames are then computationally corrected for movements of the biomolecules in ice and analyzed to yield near-atomic resolution density maps. However, even at these resolutions, tracing an RNA chain can be difficult de novo. Further analysis of cryo-EM maps using computational modeling and fitting tools such as Rosetta will be powerful, as well as incorporating reliable base-pairing data from other methods such as NMR.

Unlike the other structural methods mentioned above, cryo-EM is inherently a single-molecule method, revealing insights into potential dynamics within biological systems. Structures are built by averaging more than 1,000-100,000 individual particles that are randomly oriented within the ice of an EM grid. Computational sorting into distinct classes can distinguish different conformational or compositional states of biomolecular assembly. This process can capture the biochemical and conformational heterogeneity of the input sample at the moment of freezing. As an extension of this capability in cryo-EM, Frank and coworkers have developed rapid-mixing and freezing approaches that allow time-resolved snapshots of the ensemble of structures in a biological reaction such as translation initiation ribosome recycling (Chen et al. 2015; Fu et al. 2016; Frank 2017a). In this process, temporal information provided by other methods is essential as dynamic observations by cryo-EM alone can be skewed by observations of only structured states.

Single-molecule fluorescence methods have revolutionized the investigation of biomolecular dynamics, providing structural dynamic information without ensemble averaging (Fig. 1). Traditionally, kinetic information has been extracted by bulk spectroscopy or by chemical kinetic methods, such as rapid-mixing, stopped-flow, or quenched-flow. These methods provide a time course of the chemical and compositional changes of the system as a function of time but require initial synchronization of a reaction and suffer from ensemble averaging that masks heterogeneous pathways. In contrast, single-molecule fluorescence methods 
can be used to monitor conformational and compositional changes of biological complexes, which later can be analyzed to reveal multistep kinetics or parsed to show different pathways.

In typical single-molecule fluorescence experiments, RNAs and proteins must first be fluorescently labeled with bright, extrinsic fluorophores. Multiple biomolecules can be individually labeled using fluorophores of different colors, which can be tracked using their respective emission channel. Nucleic acids are labeled using chemical modification of synthetic oligonucleotides or chemical reaction with specifically modified ends of RNAs (for example, through oxidation of the terminal cis-diol at the $3^{\prime}$ end of an RNA). Longer (>70-nt) labeled RNAs can be specifically labeled by hybridization of a dye-labeled DNA or RNA probe or created from shorter RNAs using efficient enzymatic ligation methods. For proteins, dyes can be attached using maleimide, $\mathrm{N}$-hydroxysuccinimide (NHS), or click chemistry, where specific labeling sites are often engineered into proteins by mutagenesis. Alternatively, a short peptide sequence can be used to tag a fluorescently labeled full protein or peptide domain such as SNAP, HaloTag, and ybbR (Yin et al. 2005; Los et al. 2008; Mollwitz et al. 2012). For all these labeling approaches, the function of the modified protein must be tested, as modification of the protein (either the sequence, length, or dye labeling) may greatly perturb function. Such biochemical controls are absolutely essential for subsequent valid biophysical investigation. To prolong tracking of a single molecule over time, fluorescently labeled RNAs or their complexes are usually immobilized on an inert surface using biotinstreptavidin interactions for specificity and stability.

By observing the behavior of single molecules, complex dynamic behavior of biomolecular systems can be determined and sorted, free from ensemble averaging. Compositional dynamics can be directly monitored as a burst in fluorescence from labeled ligands that colocalize with the surface-immobilized biomolecule. To limit excitation to the immobilized molecules, total internal reflectance microscopy (TIRFM) is often used, which allows inclusion of the free fluorescent molecule in solution below $\sim 20-50 \mathrm{~nm}$ in concentration before the signal is drowned by the background noise. Different instrumentation can be used to track fluorescently labeled ligands at higher concentration. Using nanophotonic devices called "zero-mode waveguides" (ZMWs) that reduce the excitation volume by orders of magnitude, free ligand concentrations up to $\mu \mathrm{M}$ (Levene et al. 2003) can be tolerated. The ZMWs are roughly cylindrical chambers of $40-180 \mathrm{~nm}$ in diameter, with functionalized quartz bottoms to immobilize biomolecules and conductive metal side walls. In both TIRFM and ZMW setups, propagating laser excitation is quenched as it moves away from the surface, leading to high excitation only near the immobilized biomolecules. Using these experimental setups, the kinetics of ligand binding and dissociation can be measured at the single-molecule level by analyzing the statistical distribution of binding event lifetimes (dissociation rate), or times between events (association rate). Thus, simple compositional dynamics can be measured for biomolecular systems from ligand occupancy as a function of time. These approaches have been applied extensively to investigate translation, splicing, and other RNA-ligand systems (Uemura et al. 2010; Hoskins et al. 2011; Friedman and Gelles 2015).

In addition to observing the compositional dynamics, conformational dynamics in RNAs can be observed directly using Förster resonance energy transfer (FRET) between fluorophores. FRET between a specific dye pair depends on the spectral overlap of the donor and acceptor dyes and is defined by an $R_{0}$ value (distance) in which energy transfer from donor to acceptor is $50 \%$; for the standard cyanine 3 (Сy3)-Cy5 pair, $R_{0}$ is $\sim 56 \AA$. FRET efficiency depends strongly on distance $\left(1 / R^{6}\right)$, such that transfer is efficient at distances well below $R_{0}(\sim 20 \AA)$ and near zero at distances greatly exceeding $R_{0}(\sim 75-80 \AA)$. Using FRET, RNA-RNA, RNA-protein, or protein-protein distance changes can be monitored in real time. As with many single-molecule approaches, timescales of conformational fluctuations are limited by camera speeds, which generally probe dynamics in the millisecond to second range. Combining FRET with fluorescently labeled ligand binding can reveal correlations between ligand occupancy and conformational changes (Wasserman et al. 2016; Prabhakar et al. 2017).

Computational approaches are central to our understanding of biomolecular dynamics. Molecular dynamics simulations have advanced greatly over the decades since their introduction by Lifson and Levitt in the 1960s. Molecular dynamics describe macromolecular motions over a range of timescales and can strongly complement experimental measurements of dynamic fluctuations in RNA. In addition, computation can fill in great detail for models of dynamics derived from a limited number of observables. Secondary structure prediction tools have improved, providing proposed secondary structures that may be in conformational equilibrium (Zuker 2003; Reuter and Mathews 2010). De novo RNA tertiary structure modeling methods have also improved, but their power will likely reside in their ability to integrate experimental data to generate accurate models of large assemblies (Cheng et al. 2015). Genomic methods using sequencing as a readout have provided dynamics of RNA processes in vivo, including structural changes, RNA-protein interactions, and ribosomal dynamics of translation. 
A combined dynamic and structural view of RNA mechanism requires a confluence of experimental approaches. We discuss here two recent examples from our own work on RNA-protein complexes that highlight how structural and dynamic data provide mechanistic insights into HIV reverse transcription and translation.

\section{STRUCTURAL DYNAMICS OF THE RIBOSOME DURING DECODING}

Ribosomes represent the archetypical RNA-protein assembly for their complexity and functionality. From a structural point of view, prokaryotic and eukaryotic ribosomes are a massive machinery with scores of proteins decorating the core RNA molecules. The ribosome has deservedly gathered wide interest from both X-ray crystallographers and cryo-electron microscopists in the past couple of decades, revealing many functional states in different organisms (Bashan and Yonath 2008; Simonović and Steitz 2009; Voorhees and Ramakrishnan 2013; Frank 2017b; Yusupova and Yusupov 2017). The ribosome is not only a ribozyme with its catalytic activities driven by a conserved RNA core, but it also has a great specificity of selecting a right transfer RNA (tRNA) substrate out of a pool of structurally similar tRNAs via just three RNA base-pairing interactions. This remarkable specificity has led to the careful early enzymatic study of accuracy and efficiency of ribosomes (Gorini 1971), which inspired the concept of the kinetic proofreading that is applicable to many other biological systems involving a substrate selection mechanism (Hopfield 1974; Ninio 1975).

The combined kinetic and structural work has led to deep understanding of the ribosome and the decoding process of messenger RNA (mRNA). Yet initially, two different methodologies to study the ribosome have resulted in distinct views of ribosomal mechanics, in which two languages coexisted to describe the molecular process of translation. From the structural view, translation was described by distinct conformational changes and domain movements at different functional states. Description of these structural changes needed to be linked with the preexisting kinetic description of translation, in which multiple structurally distinct substates have been proposed to explain highly accurate and efficient translation. Single-molecule methods have been critical to link high-resolution structural and kinetics experiments. To show our case in point, we will discuss our recent works on the effect of mRNA modifications in translation, combining results from single-molecule, bulk kinetics, and X-ray crystallography methods (Fig. 2).

\section{MODULATION OF TRANSLATION DECODING DYNAMICS BY $\mathrm{m}^{6} \mathrm{~A}$ mRNA MODIFICATIONS}

Although no less than 160 distinct natural RNA modifications are known to exist in the transcriptome (Boccaletto et al. 2018), investigation into the roles of these modified

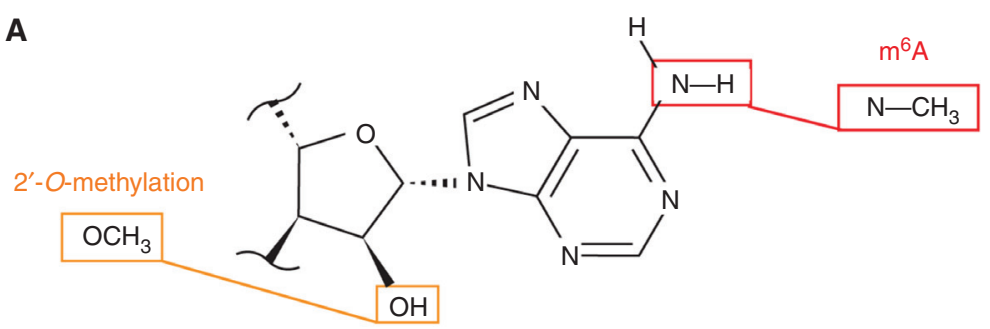

B

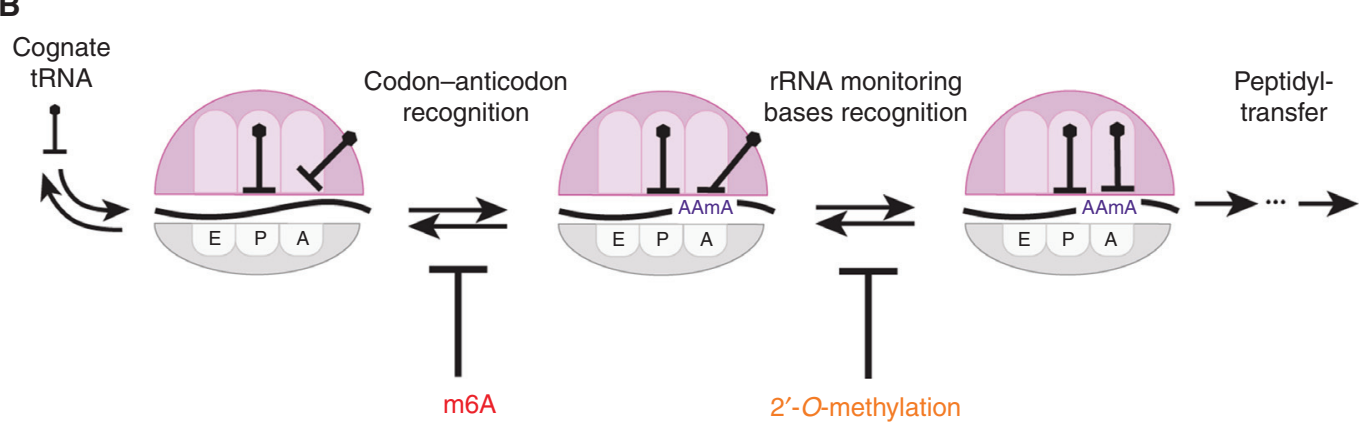

Figure 2. Effect of $N^{6}$-methyladenosine $\left(\mathrm{m}^{6} \mathrm{~A}\right)$ and $2^{\prime}-O$-methylation on translation elongation. $(A) \mathrm{m}^{6} \mathrm{~A}$ methylates one of two hydrogens on $N^{6}$, whereas $2^{\prime}$-O-methylation occurs on $2^{\prime}-\mathrm{OH}$ of RNA ribose. $(B) \mathrm{m}^{6} \mathrm{~A}$ inhibits initial codon-anticodon helix formation after binding of the cognate tRNA to the translating ribosome. $2^{\prime}$-O-methylation inhibits dynamics of hydrogen bonding between rRNA-monitoring bases and the mRNA-tRNA helix. 
nucleotides in mRNA has recently exploded with the discovery of RNA modifications that were reversible. The first reversible modification in mRNA to be discovered was the modification of adenosine (A) to $N^{6}$-methyladenosine $\left(\mathrm{m}^{6} \mathrm{~A}\right)$ (Dominissini et al. 2012; Meyer et al. 2012), in which one of two hydrogens attached to the $N^{6}$ of A is methylated (Fig. 2A). The $\mathrm{m}^{6} \mathrm{~A}$ modification of mRNA was shown to be dynamically regulated by the modifier ("writer") and the demodifier ("eraser") proteins, which in turn, controls its recognition by a set of its associated proteins ("reader"). This possible dynamic regulation of mRNA modification has launched the field of epitranscriptomics (or RNA epigenetics) (He 2010; Saletore et al. 2012) and made $\mathrm{m}^{6} \mathrm{~A}$ a subject of intense studies. $\mathrm{m}^{6} \mathrm{~A}$ has been shown to participate in diverse translational regulation processes, in which its presence affects translation initiation, elongation, and the mRNA decay (Roundtree et al. 2017). Yet, in addition to recognition of $\mathrm{m}^{6} \mathrm{~A}$ by its reader proteins, the base-pairing between $\mathrm{m}^{6} \mathrm{~A}$ and uridine $(\mathrm{U})$ is weaker than that between $\mathrm{A}$ and $\mathrm{U}$, disrupting the formation of RNA secondary structures harboring $\mathrm{m}^{6} \mathrm{~A}$ within their RNA helix (Roost et al. 2015). Yet, such base-pairing interactions are essential for the codon recognition. Then, how would the translational machinery respond when there is $\mathrm{m}^{6} \mathrm{~A}$ present within the coding region?

To answer this question, compositional and conformational dynamics of the ribosome during in vitro translation were monitored using a single-molecule fluorescence assay (Choi et al. 2016). Previous structural methods have shown that when a codon is read by tRNA and the nascent peptide is elongated by one amino acid attached to the tRNA, the ribosome undergoes a conformational change from nonrotated state to rotated state (also referred to as the change from classical state to hybrid state) (Moazed and Noller 1989; Frank and Agrawal 2000). The resulting rotated state transitions back to the nonrotated state after translocation, which physically moves the ribosome to the next codon for decoding. By attaching a pair of FRET probes to the ribosome, the kinetics of its conformational change on a successful decoding event can be measured on each codon by measuring the lifetime of FRET states (Dorywalska et al. 2005; Aitken and Puglisi 2010). The ribosome conformational signal can be further fortified by the use of fluorescently labeled tRNA, which serves as an orthogonal probe for both successful and futile tRNA-binding events during decoding.

Slower decoding kinetics due to the increased rejection of tRNA was observed on a single-nucleotide $\mathrm{m}^{6} \mathrm{~A}$-modified codon compared with that of the unmodified codon (Choi et al. 2016). The magnitude of change in kinetics varied by its context within the modified codon: The maximal effect of 15-fold slower decoding kinetics was observed on the $m^{6}$ AAA codon, whereas modifications at the second or third position or the increase in G-C content of the codon decreased the effect. The sensitivity of the modification effect to the codon context was interesting, as it suggested the maximal accuracy of the particular codon-anticodon interaction is changing with the modification (Johansson et al. 2012). Using bulk kinetics methods, we showed a change in decoding kinetics caused by the presence of $\mathrm{m}^{6} \mathrm{~A}$ in a codon with higher precision and temporal resolution.

The next question was to understand how $\mathrm{m}^{6} \mathrm{~A}$ slows decoding kinetics structurally. Using X-ray crystallography, structures of the ribosomal decoding center were solved while programmed with the tRNA anticodon stem loop and with three different single-nucleotide $\mathrm{m}^{6} \mathrm{~A}$-modified AAA codons at each nucleotide position (Choi et al. 2016). When compared with the canonical A-U base pair in the codon-anticodon helix, there was no observable difference between $\mathrm{A}$ and $\mathrm{m}^{6} \mathrm{~A}$ while base-paired with $\mathrm{U}$ : The methyl moiety of $\mathrm{m}^{6} \mathrm{~A}$ is simply turned away from the Watson-Crick edge between A and U. This result seemed quite incongruous with our kinetics results: How could $\mathrm{m}^{6} \mathrm{~A}$ affect kinetics of decoding while being structurally similar to A when base-pairing with the same U?

One possible explanation was that because only one $\mathrm{N}^{6}$ hydrogen moiety is available for $\mathrm{m}^{6} \mathrm{~A}$ to participate in the hydrogen bond instead of two in the unmodified $\mathrm{A}$, the $\mathrm{m}^{6} \mathrm{~A}-\mathrm{U}$ base pairs are weaker than the A-U base pair in the codon-anticodon helix, similar to what was observed in the RNA helix by NMR (Roost et al. 2015). To test this hypothesis, the binding stability of tRNA to the ribosome was directly measured by fluorescently labeling two adjacent tRNAs with FRET probes while decoding the $\mathrm{m}^{6} \mathrm{~A}$ modified codon. In addition, different small molecules were added to the experiment to probe various substeps of decoding. The most relevant small molecule was the antibiotic tetracycline, which prevents decoding after the initial codon recognition by the anticodon loop of tRNA (Blanchard et al. 2004). The $\mathrm{m}^{6} \mathrm{~A}$-modified codon was observed to hasten the dissociation of tRNA in the presence of tetracycline, which suggested that the codon-anticodon interaction is weakened by the presence of $\mathrm{m}^{6} \mathrm{~A}-\mathrm{U}$ base pair.

In this study, combinations of structural and kinetic methods were used to reveal that the presence of $\mathrm{m}^{6} \mathrm{~A}$ modification within the mRNA weakens the codon-anticodon interaction and slows down translation elongation kinetics (Fig. 2B). Particularly, single-molecule methods were used to bridge the contrasting observations made in the structural and bulk kinetics methods, by directly monitoring the kinetics of structural compositional changes during translation. Yet, it is still not clear how slower decoding kinetics are linked with the regulatory role of $\mathrm{m}^{6} \mathrm{~A}$ in the mRNA coding region. Perhaps, the modulation of translation elongation dynamics by mRNA modification coordinates the various cotranslational events such as protein folding, 
nascent peptide recognition, etc. In this scenario, $\mathrm{m}^{6} \mathrm{~A}$ may not be the only modification that is used to modulate the translation elongation kinetics, but other naturally occurring modifications within the coding region of mRNA may serve similar roles.

\section{MODULATION OF TRANSLATION DECODING DYNAMICS BY 2'-O-METHYLATION}

$2^{\prime}$-O-methylation is a recent addition to the growing list of chemical modifications discovered to occur in mRNA. Unlike other known mRNA modifications, 2'-O-methylation alters the $2^{\prime}-\mathrm{OH}$ moiety of the ribose, rather than changing the nucleoside base and may arguably be the most interesting part of the molecule as it distinguishes RNA and DNA (Fig. 2A). Therefore, many distinct characteristics of RNA are linked with the $2^{\prime}-\mathrm{OH}$ group, such as preference for an A-form helical conformation, formation of the tertiary structure through hydrogen bonding with the $2^{\prime}-\mathrm{OH}$ group, and the enzymatic activity of RNA related to the hydrolysis via $2^{\prime}-\mathrm{OH}$. The last point has been a particular disadvantage to work with RNA, which led to techniques such as substituting the entire $2^{\prime}-\mathrm{OH}$ moieties of RNA oligonucleotide with synthetically $2^{\prime}$-O-methylated nucleotides for resisting RNA hydrolysis (Kraynack 2006). Biophysical studies of 2'-O-methylated RNA has shown that it enhances the helix formation to a complementary RNA or $2^{\prime}$-O-methylated strand (Cummins et al. 1995). The resistance to chemical reaction by $2^{\prime}-\mathrm{OH}$ has been used to detect $2^{\prime}-\mathrm{O}$-methylation within mRNA (Dai et al. 2017). The cellular mRNA is purified and subject to multiple cycles of a chemical treatment, which requires the $2^{\prime}-\mathrm{OH}$ moiety of mRNA to eliminate its presence before the high-throughput sequencing. This has resulted in the map of 2'-O-methylation occurring in mRNA, which is strongly enriched in the coding region, as well as codon preference and nucleotide preference within the enriched codon.

The enriched presence of $2^{\prime}$-O-methylation in the coding region of mRNA raises the question of its role during translation elongation. To understand how 2'-O-methylated codon affects translation, we took a similar approach as discussed above for $\mathrm{m}^{6} \mathrm{~A}$ : First, the decoding kinetics of a single-nucleotide 2'-O-methylated codon was measured using single-molecule and bulk kinetics assays and compared with that of an unmodified codon (Choi et al. 2018). Surprisingly, a substantially delayed tRNA accommodation on the $2^{\prime}$-O-methylated codon was observed, more than an order of magnitude slower than observed with the $\mathrm{m}^{6} \mathrm{~A}$ modification, reaching at most 1500 -fold slower kinetics compared with that of the unmodified codon. The magnitude of delay by $2^{\prime}-O$-methylation was also dependent on its codon context, but its pattern was different from that of $\mathrm{m}^{6} \mathrm{~A}$. The largest effect of $2^{\prime}$-O-methylation was observed when the second nucleotide position of a codon was modified, rather than at the first nucleotide position as in $\mathrm{m}^{6} \mathrm{~A}$ modification. The delayed decoding accompanied multiple tRNA sampling events in the order of 0.1 to $1 \mathrm{sec}$ before a successful accommodation, unlike short tRNA sampling events with $\mathrm{m}^{6} \mathrm{~A}$ that were too transient to be directly observed with the temporal resolution of $0.1 \mathrm{sec}$. This suggested that $2^{\prime}-$ $O$-methylation affects decoding after the initial codon-anticodon formation, in which the codon-anticodon interaction would lengthen the tRNA-bound time before its rejection.

How could this large perturbation to decoding kinetics be explained in terms of the ribosome structure? During tRNA decoding, the ribosome checks the geometry of the initial codon-anticodon helix formation via binding of ribosomal RNA (rRNA) to the 2'-OH of mRNA (Yoshizawa 1999; Ogle et al. 2001; Ogle et al. 2002). Thus, the substitution of 2'-OH with 2'-O-methyl moiety might alter the kinetics of ribosome recognition of a correctly formed codon-anticodon helix (Fig. 2B). This notion was supported by the structure of the ribosome decoding center harboring the 2'-O-methylated codon, obtained using Xray crystallography (Choi et al. 2018). These structures showed a significant distortion between the interacting rRNA and the mRNA 2'-O-methyl group. The distortion was most pronounced when the second nucleotide position of the codon is $2^{\prime}-O$-methylated, matching the pattern of the pause duration as a function of position of the modification observed in the single-molecule assay.

Similar to the $\mathrm{m}^{6} \mathrm{~A}$ modification, the biological role of delaying translation elongation by $2^{\prime}-O$-methylation is not clear. The enrichment in the coding region, the codon preference as well as the preferred nucleotide position of 2'-Omethylation suggests its role during translation elongation (Dai et al. 2017). The presence of either $\mathrm{m}^{6} \mathrm{~A}$ or $2^{\prime}-\mathrm{O}$-methylation modification may be used to fine-tune translation elongation kinetics and regulate the protein synthesis. The magnitude of the delay created by $2^{\prime}-O$-methylation, however, may exceed the tolerance of translation, and lead to other translation control processes that abort translation and subject the mRNA transcript to degradation (Zaher and Green 2009). Genes that are directly regulated by altering translational decoding kinetics have not yet been discovered, and the role of 2'-O-methylation within the coding region still remains elusive.

\section{NEXT STEPS IN STUDYING THE ROLE OF mRNA MODIFICATION IN TRANSLATION DECODING}

In the past decade, we have observed a rapid advance in methods to detect cellular RNA modifications (Linder and Jaffrey 2019). However, their biological roles in translation 
decoding remain unresolved. In addition to changing elongation dynamics, RNA modifications change the context of a modified codon and induce miscoding events (Karijolich and $\mathrm{Yu}$ 2011; Fernandez et al. 2013). It is plausible that different modes of regulation exist for controlling gene expression by posttranscriptional modifications. Different mRNA modifications may modulate structural dynamics of a translational complex. As such, we may learn more about mechanisms of translation by using mRNA modifications as a tunable perturbation to the canonical pathway. Combinations of structural and kinetic methods will be a powerful tool in this effort.

\section{STRUCTURAL DYNAMICS OF HIV-1 REVERSE TRANSCRIPTION INITIATION}

Reverse transcription, discovered in 1970, is the process by which RNA is copied into a double-stranded DNA (Baltimore 1970; Temin and Mizutani 1970). Although found in eukaryotic systems in the form of retrotransposons and telomere lengthening, the deepest study has been in retroviral replication, in particular for human immunodeficiency virus 1 (HIV-1) (Gilboa et al. 1979; Hu and Hughes 2012). In HIV-1, a virally encoded enzyme, reverse transcriptase (RT), binds an 18 base pair intermolecular primer-binding site (PBS) helix formed between a primer tRNA $_{3}^{\text {Lys }}$ and the positive-sense genomic viral RNA (vRNA) (Fig. 3A) (Ratner et al. 1985; Isel et al. 2010). Early studies on HIV-1 reverse transcription distinguished its initiation step from the later elongation phases owing to its unique kinetic properties (Isel et al. 1996; Lanchy et al. 1996). The polymerization rate of RT appears to be 100 500-fold slower during initiation than during elongation, with pausing events causing a buildup of discrete, partially extended products (Fig. 3B) (Lanchy et al. 1996; Suo and Johnson 1997a; Suo and Johnson 1997b; Liang et al. 1998; Goldschmidt et al. 2002). RT also has a higher dissociation rate from its initiation RNA-RNA substrate than later DNA-DNA and DNA-RNA elongation substrates (Kati et al. 1992; Lanchy et al. 1996; Suo and Johnson 1997b; Vaccaro et al. 1999; Goldschmidt et al. 2002; Marko et al. 2013; Coey et al. 2018).

The structural, biophysical, and biochemical basis for the RT polymerization cycle during elongation has been deeply established over the past decade (Sarafianos et al. 2009). Bulk steady state, pre-steady state, and single-turnover kinetics delineated the mechanism of deoxynucleotide triphosphate (dNTP) incorporation and fidelity (Kati et al. 1992; Isel et al. 1996; Lanchy et al. 1996; Suo and Johnson 1997a; Liang et al. 1998; Li et al. 2016). Structural studies defined the architecture of RT, a two-subunit (p51 and p66) polymerase, showed how double-stranded DNA substrates bound in a long cleft made by the p66 subunit, and how RT inhibitors bind and affect enzymatic function (Sarafianos et al. 2009). Despite this structural and biochemical context, how HIV-1 navigates the very initial phase of reverse transcription has remained unresolved.

The mechanisms governing the unique properties of the initiation phase of HIV-1 reverse transcription were initially explored using biochemical approaches. RNA mutagenesis, RNA chemical/enzymatic mapping studies, and kinetics assays were used to characterize the contributions of RNA sequence and structure in the vRNA-tRNA ${ }_{3}^{\text {Lys }}$ binary complex (Isel et al. 1995; Isel et al. 1996; Lanchy et al. 1996; Liang et al. 1997; Lanchy et al. 1998; Liang et al. 1998; Isel et al. 1999; Vaccaro et al. 1999; Lanchy et al. 2000; Beerens et al. 2001; Beerens and Berkhout 2002b; Goldschmidt et al. 2002; Goldschmidt et al. 2003; Iwatani et al. 2003; Goldschmidt et al. 2004). HIV-1 vRNA has a region of 18 nucleotides (nt) that are complementary to the $3^{\prime}$ end of tRNA ${ }_{3}^{\text {Lys }}$, which forms the PBS helix that serves as the initial binding site for RT. In addition to the PBS helix, these studies showed that HIV-1 vRNA is highly structured, and there was convincing evidence to suggest additional regions of sequence complementarity between the tRNA and vRNA that extended outside of the PBS sequence (Fig. 3C) (Isel et al. 1995; Isel et al. 1999; Lanchy et al. 2000; Goldschmidt et al. 2002; Goldschmidt et al. 2003; Goldschmidt et al. 2004; Paillart et al. 2004). Mutations within these sequences drastically altered initiation kinetics, decreased virus viability, and appeared to alter the vRNA-tRNA fold (Liang et al. 1997; Isel et al. 1998; Liang et al. 1998; Beerens and Berkhout 2002a; Beerens and Berkhout 2002b; Goldschmidt et al. 2002; Goldschmidt et al. 2003; Iwatani et al. 2003; Goldschmidt et al. 2004; Ooms et al. 2007). These data suggested that the vRNA and tRNA rearrange to form additional structures outside of the PBS helix that are vital in controlling initiation (Fig. 3C). The first and most widely studied of these structures was an A-rich loop sequence in the vRNA, which was proposed to pair with the anticodon of the $\operatorname{tRNA}^{\mathrm{Lys}}{ }_{3}$ (Isel et al. 1993; Liang et al. 1997; Isel et al. 1998; Puglisi and Puglisi 1998; Bilbille et al. 2009). Additional sequences, like the primer activation signal (PAS) sequence within helix 1 (H1) of the vRNA, and a C-rich region in vRNA helix 2 $(\mathrm{H} 2)$, were also identified and have complementary sequences respectively located within the tRNA T-loop and variable loop (Fig. 3C) (Beerens and Berkhout 2002b; Iwatani et al. 2003). However, attributable to the limited structural information of these bulk studies, an understanding of the timing of such rearrangements and the possibility of multiple coexisting RNA conformations remained speculative. More detailed structural information using modern methods were needed to parse RNA heterogeneity and the 
A

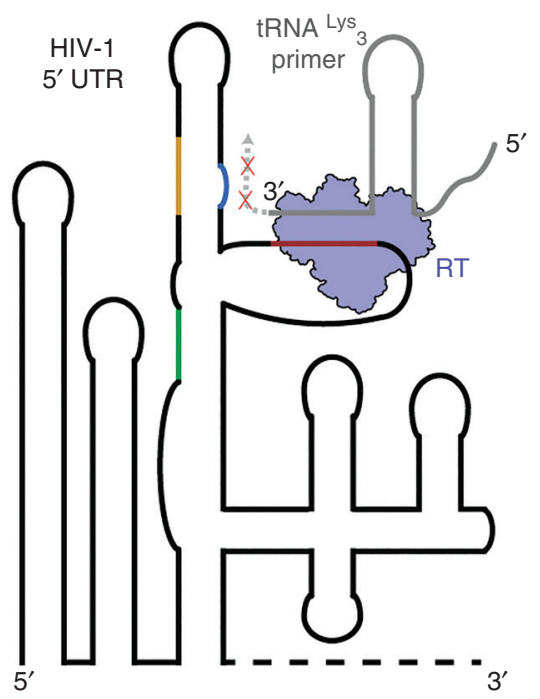

B

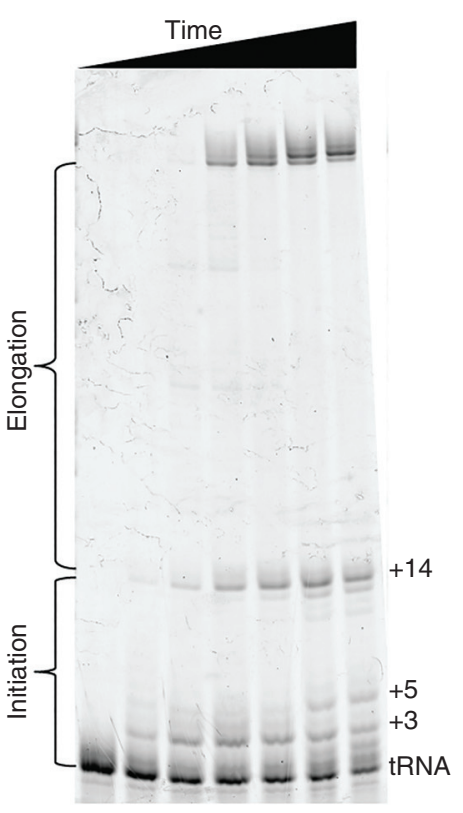

C

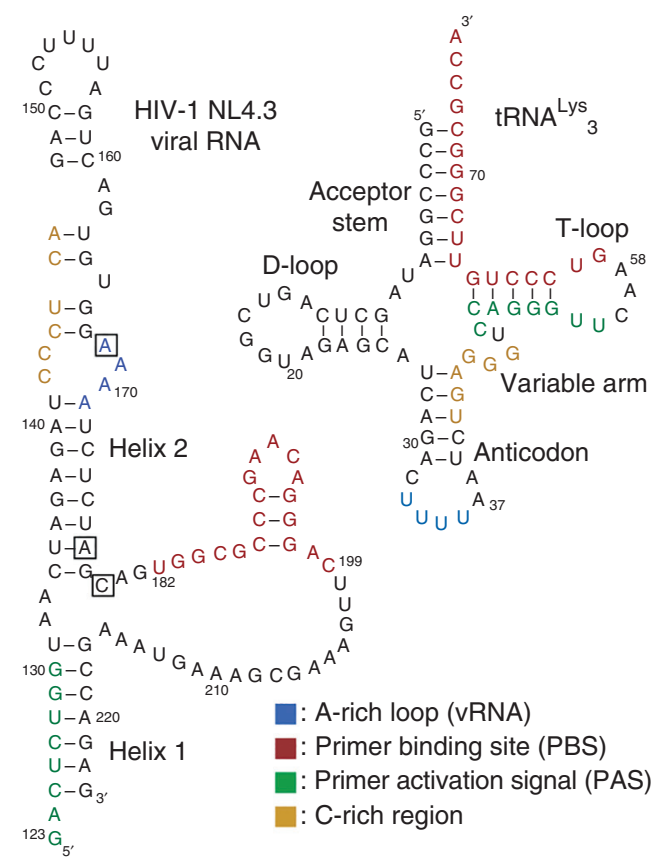

D

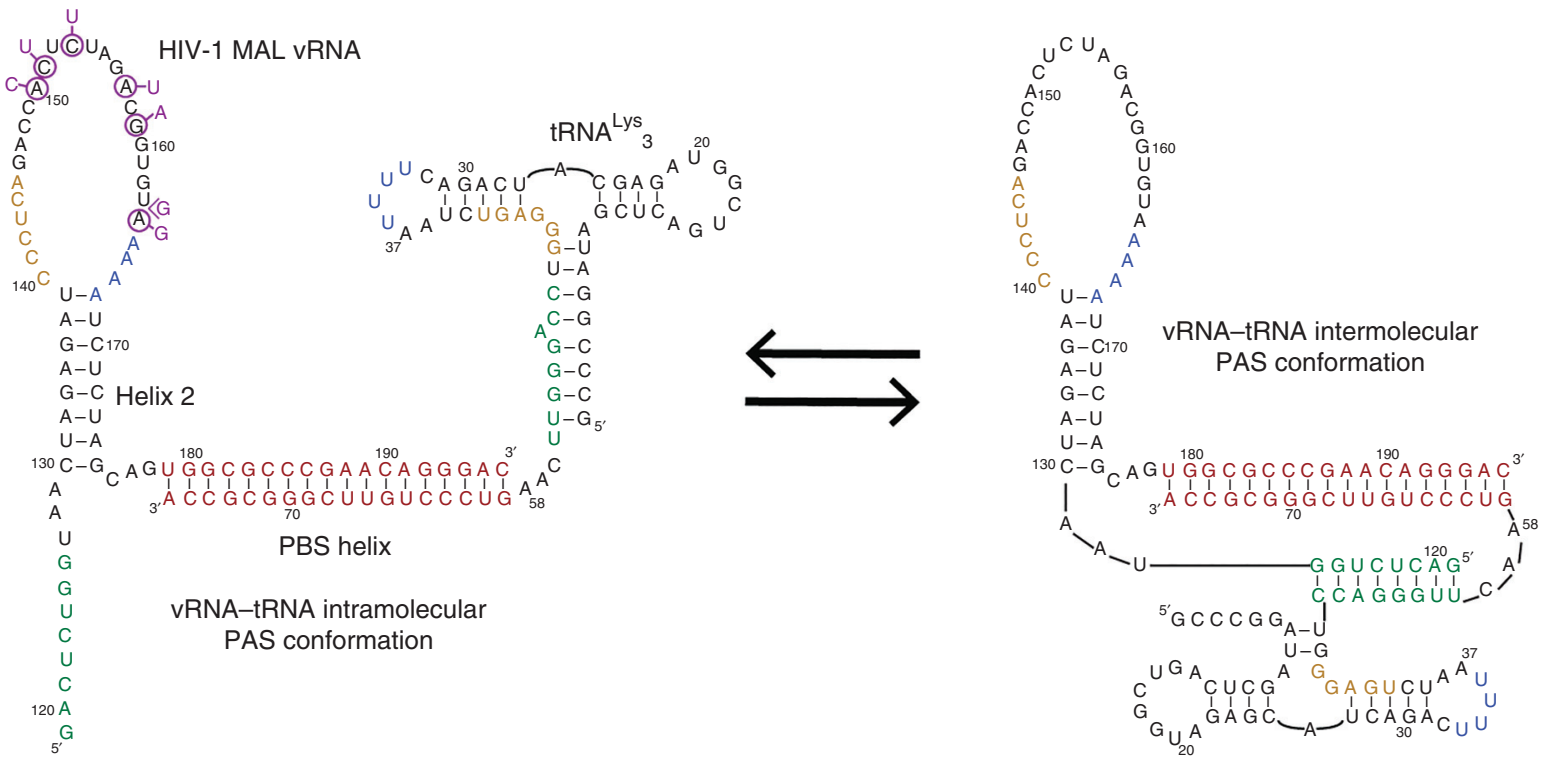

Figure 3. (A) Reverse transcriptase (RT) must bind an 18-base-pair helix formed between the tRNA primer and the $5^{\prime}$ untranslated region (UTR) of the viral RNA genome (vRNA). The primer-binding site (PBS) helix resides in a highly structured region of the vRNA genome. RT has a rapid dissociation rate from the PBS helix and shows discrete pausing events during initiation $(\mathrm{red} \times \mathrm{s})$. (B) A primer extension gel in which polymerase extension reactions of RT for the vRNA-tRNA complex have been quenched at different time points. Unextended tRNA runs at the bottom of the gel and fully extended primer runs near the top. The buildup of pausing products can be seen in the lower half of the gel. $(C)$ Secondary structures of the tRNA ${ }_{3}^{\text {Lys }}$ primer and the NL4.3 human immunodeficiency virus 1 (HIV-1) subtype genome PBS region vRNA. Regions of sequence complementarity have been colored. Nucleotide positions that correspond to the pausing points seen in $B$ are boxed on the vRNA. (D) NMR-derived structures of the MAL HIV-1 subtype genome in complex with the tRNA primer. Complementary sequences are colored as in $C$. Nucleotide mutations in MAL compared with NL4.3 are indicated in purple. 
timings of these structural rearrangements. We will discuss work from our laboratory and others that illustrates how traditional RNA structural methods can be coupled with single-molecule experimentation to elucidate the dynamics of a complex multicomponent system.

\section{HIV-1 VIRAL RNA-tRNA ${ }_{3}^{\text {Lys }}{ }_{3}$ COMPLEX STRUCTURE AND HETEROGENEITY}

The Marquet laboratory used a combination of chemical and enzymatic mapping methods to generate secondary structure models of the vRNA-tRNA ${ }_{3}^{\text {Lys }}$ complex (Isel et al. 2010). These studies were often combined with functional assays in an attempt to determine the vRNA structures responsible for influencing initiation kinetics. These predicted models relied on comparison to the free forms of vRNA and tRNA ${ }_{3}^{\text {Lys }}$ and were often interpreted to maximize the possible interactions between the two components. Initial efforts attempted to explore RNA dynamics and structural rearrangements by performing similar experiments on pre-extended or stalled complexes in the presence or absence of RT (Lanchy et al. 1998; Lanchy et al. 2000; Isel et al. 2010). From these groundbreaking experiments, the concept that the conformation of the initiation complex evolved structurally over time began to emerge. However, because of the bulk nature of these experiments, information on RNA structural heterogeneity was lost. A later study by Beerens et al., using single-molecule FRET, suggested that the vRNA-tRNA complex exists in several structures that can undergo conformational changes related to the PAS interaction (Beerens et al. 2013). The labeling scheme only monitored vRNA H1 formation and melting, thus this study did not directly reveal the formation of new stable vRNA-tRNA structures.

To probe the extent of structural heterogeneity and dynamics in the vRNA-tRNA complex, we have used a combination of NMR spectroscopy and single-molecule fluorescence methods (Puglisi and Puglisi 2011; Coey et al. 2016, 2018). Because of the size limitations of NMR spectroscopy, these studies focused on a minimal vRNA system containing the PAS and/or A-rich loop sequences (Fig. 3D). The first NMR study determined the secondary structure of the vRNA-tRNA complex, which showed extensive tRNA remodeling and the existence of a vRNA hairpin, $\mathrm{H} 2$, immediately downstream from the PBS $(\mathrm{Pu}-$ glisi and Puglisi 2011). However, the NMR experiments did not reveal additional vRNA-tRNA interactions outside of the PBS helix. This study was extended by increasing the size of the vRNA construct at its $5^{\prime}$ end to include the downstream PAS sequence (Coey et al. 2016). These NMR experiments identified two potential conformations of the vRNA-tRNA complex, with the first being similar to the results in Puglisi et al. However, an additional structure was identified that was consistent with formation of the intermolecular PAS helix between the vRNA and tRNA in slow exchange (slower than $100 \mathrm{msec}$ timescale). To investigate the dynamics of this system, a single-molecule FRET experiment was designed to directly monitor the formation of the intermolecular PAS helix. These experiments showed that the vRNA-tRNA complex existed in two distinct conformations, with either intra- or intermolecular PAS formation (Fig. 3D). Additional NMR and single-molecule experiments confirmed that the intermolecular PAS helix coexisted with a formed PBS helix and the downstream vRNA H2. The two PAS conformations appeared to be extremely stable and in very slow exchange, on the order of minutes. These results suggest that RT encounters a variety of RNA conformations that it must navigate, and possibly remodel, during initiation. RNA structure could thus serve as a regulation mechanism during initiation.

The results discussed above showed the influence that RNA construct length can have in general on structural and biophysical studies. We subsequently lengthened the vRNA construct to replicate better the functional aspects of reverse transcription initiation (Coey et al. 2018). The vRNA sequence was extended both upstream of and downstream from the PBS region to include the full HIV-1 intramolecular PAS helix, dubbed H1 (Fig. 3C). To determine further the extent of the vRNA-tRNA complex dynamics, an additional FRET-labeling scheme was used to probe the spatial relationship between the tRNA $5^{\prime}$ end and vRNA H1. FRET probes were placed on the vRNA $5^{\prime}$ or $3^{\prime}$ ends (H1) and on the tRNA $5^{\prime}$ end. These experiments showed a diverse range of FRET values and states, indicative of conformational dynamics between the structural domains of the vRNA-tRNA complex (Fig. 4). The different conformations interconvert on short $(2-4-\mathrm{sec})$ and long $(>10-\mathrm{sec})$ timescales, supporting a model that the vRNA-tRNA complex is structurally dynamic in the absence of RT.

These experiments have begun to delineate the vRNAtRNA structural landscape that exists in the absence of RT binding. NMR and single-molecule experiments directly revealed the ability of the vRNA-tRNA complex to form additional structures without perturbing the PBS helix and vRNA H2. Additional single-molecule experiments explored the structural dynamics of the vRNAtRNA by monitoring the spatial relationship between vRNA $\mathrm{H} 1$ and the tRNA $5^{\prime}$ end (Fig. 4). This further revealed the extensive conformational heterogeneity and structural interconversion of the RNA elements. To delineate the interplay of structure and dynamics of the initiation complex, additional experiments introducing RT were required. 


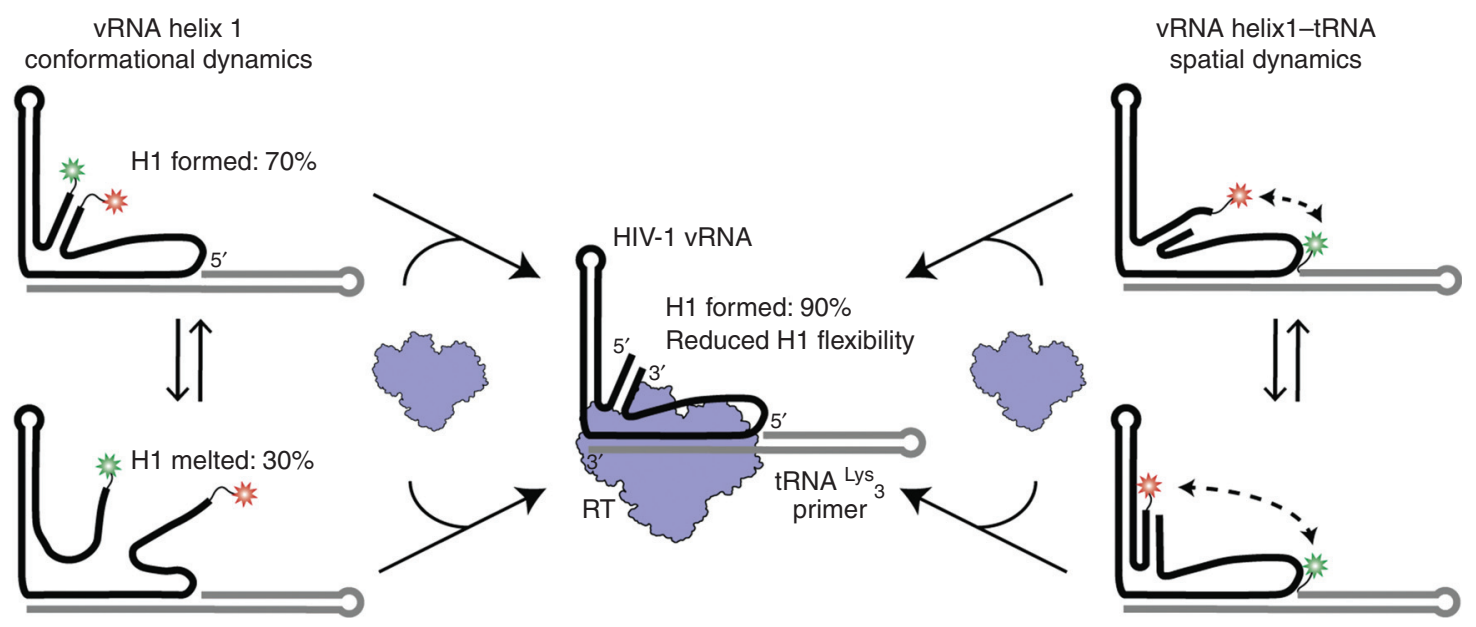

Figure 4. The conformational heterogeneity observed in the vRNA-tRNA complex is reduced on the introduction of reverse transcriptase (RT). (Left) Viral RNA helix 1 (vRNA H1) formation was monitored in the absence and presence of RT by labeling the vRNA on its $3^{\prime}$ and $5^{\prime}$ ends. Two main populations were observed. (Right) The spatial orientation of $\mathrm{H} 1$ and the tRNA was monitored by labeling vRNA H1 and the $5^{\prime}$ end of the tRNA. A variety of interconverting high and low FRET populations were observed, indicating conformational dynamics. (Center) Upon RT binding, we observed a reduction in the conformational and structural heterogeneity for vRNA H1. FRET populations shifted to indicate $90 \% \mathrm{H} 1$ formation and the FRET populations for the vRNA-tRNA dynamics shifted to all low FRET states. (Data adapted from Coey et al. 2018.)

\section{INTERACTIONS OF HIV-1 RT WITH THE PRIMER-TEMPLATE COMPLEX}

HIV-1 RT is the enzyme responsible for not only reverse transcribing the entire viral RNA genome into DNA, but also degrading the RNA after copying has occurred. The prominent and key role RT plays in HIV-1 replication has caused it to be a widely studied drug target in AIDS therapies (Sarafianos et al. 2009). Thus, there are decades of structural and mechanistic data on RT and how it interacts with nucleic acid substrates. RT is a heterodimer with its smaller, structural p51 subunit being a truncation of its catalytic p66 subunit. The p66 subunit contains both of the enzyme's polymerase and RNase $\mathrm{H}$ active sites. The polymerase domain contains 4 subdomains (fingers, palm, thumb, and connection) that adopt a classic polymerase fold. Numerous crystal structures, with a wide range of inhibitors, DNA-DNA substrates, and DNA-RNA substrates, have revealed distinct functional states for RT (Huang et al. 1998; Sarafianos et al. 2001; Das et al. 2012; Das et al. 2014). This work has provided a detailed mechanistic understanding of how RT interacts with and extends elongation substrates. Although this repertoire of information is vast, the interaction of RT with the vRNA-tRNA complex during initiation has been poorly understood.

Extensive work has suggested that interactions of RT with the vRNA-tRNA complex, specifically those near the polymerase active site, govern the transition from initi- ation into elongation (Lanchy et al. 1998; Lanchy et al. 2000). Once the tRNA primer had been extended 6-9 nt, RT processivity increased because of inversely correlated changes in the polymerization rate $\left(k_{\mathrm{pol}}\right)$ and the dissociation rate $\left(k_{\text {off }}\right)$ of RT for the extended substrates (Lanchy et al. 1998; Lanchy et al. 2000; Liu et al. 2010). However, the exact nature of the RT-nucleic acid interactions near the active site has remained a mystery. This is further convoluted because of the possible structural rearrangements in the vRNA-tRNA complex; the growing primer strand, extended by RT, perturbs the vRNA helixes downstream from the PBS. The nature of the helical structure with the RTbinding cleft also changes from an RNA-RNA duplex to RNA-DNA, which may also affect the accommodation of substrate in the active site. This suggests a highly dynamic process in which vRNA-tRNA conformation evolves temporally as RT alters primer composition through extension. An additional layer of complexity came in the form of a single-molecule FRET study by Liu et al. (2010), which showed that RT has two distinct binding modes on the vRNA-tRNA initiation complex. Their experimental setup monitored RT-binding orientations to the vRNA-tRNA complex in a variety of conditions. They concluded that there existed an "active" orientation with the polymerase active site located near the tRNA $3^{\prime}$ end or an "inactive" flipped orientation with the RNase $\mathrm{H}$ active located near the tRNA $3^{\prime}$ end. These binding preferences were correlated with polymerase activity, the enzyme preferring to reside 
in the flipped orientation on preextended complexes that showed a low $k_{\text {pol }}$. The transition between +5 and +6 showed an approximately fivefold increase on the equilibrium constant between the polymerase-competent and flipped orientations and an approximately fourfold increase in $k_{\text {pol }}$. The polymerase-competent orientation also appeared to be favored when vRNA $\mathrm{H} 2$ was disrupted and an additional FRET experiment showed that this disruption occurs after incorporation of the sixth nucleotide into the growing primer strand (Liu et al. 2010).

We have explored how RT can interact with the vRNAtRNA complex to alter the dynamics of the HIV-1 initiation complex (Coey et al. 2018). Instead of focusing on RTbinding orientation, we determined the effect of RT binding on RNA structure. Experiments were performed using two FRET-labeling schemes that were used to study the free vRNA-tRNA complex above (Fig. 4). Using the vRNA 3'and $5^{\prime}$-labeled scheme, we monitored the influence of RT binding on $\mathrm{H} 1$ formation within the vRNA-tRNA. In the absence of RT, helix formation as signified by high FRET, was found to occur in $70 \%$ of molecules. This population shifted to $90 \% \mathrm{H} 1$ formation after the introduction of excess unlabeled RT. Such a shift suggested that RT binding was able to modulate the structural heterogeneity of the vRNAtRNA complex. In addition, RT was added to FRET experiments that monitored the spatial orientation of vRNA H1 and the tRNA $5^{\prime}$ end (Fig. 4). In the absence of RT, these two RNA domains appeared to be highly dynamic with respect to each other with numerous interconverting FRET states. However, on the introduction of RT, the FRET population distribution shifted entirely to low FRET states. These sets of experiments highlighted the ability of RT to alter the conformational landscape of the vRNA-tRNA and reduce its structural heterogeneity in terms of secondary structure and spatial orientation (Fig. 4).

\section{INSIGHTS INTO THE TERTIARY STRUCTURE OF THE HIV-1 RT INITIATION COMPLEX}

As highlighted in the preceding sections, decades of work have attempted to understand the molecular mechanism of the HIV-1 reverse transcription initiation (Isel et al. 2010). The distinct aspects of initiation compared with elongation were underscored by kinetics measurements that showed its nonprocessive nature and discrete pauses. Detailed investigations of the sequence and secondary structure of the vRNA-tRNA complex yielded the discovery of additional interactions between regions on the vRNA and tRNA outside of the PBS helix. Single-molecule experiments underscored the structural variability and dynamics contained within the vRNA-tRNA and the vRNA-tRNA-RT complexes (Liu et al. 2010; Beerens et al. 2013; Coey et al. 2016; Coey et al. 2018). Despite these advances, there remained a lack of detailed structural information on the RT initiation complex (RTIC) outside of secondary structure models.

Recently, we determined the tertiary structure of a RTIC using cryo-EM and a cross-linking approach, similar to that used in Huang et al. (2000), to stabilize and trap a +1 extended state complex (Fig. 5A) (Larsen et al. 2018). This RTIC was formed using a 101-nt fragment of vRNA that encompasses all of the structural elements believed to interact with the tRNA primer during initiation (Figs. 3C and 5). The cryo-EM study resulted in two main electron density maps. The first, which best describes the global architecture of the HIV-1 RTIC, was limited to a global resolution of 8.0 A because of the flexibility of the RNA elements. The second map, at a resolution of $4.5 \AA$, was derived by masking away the peripheral flexible RNA elements and focused on refining the core of RT and the RNA within its binding cleft. Together, these maps provided sufficient information to build a global model encompassing nearly all of the vRNA-tRNA elements as well as RT (Fig. 5A). The RNA domains were generated using Rosetta based on previously derived secondary structure models for the vRNA. Although this approach does not provide exact information on base pairs and detailed local conformations, it was able to shed light on the global fold of the RNA within the RTIC.

The global RTIC structure featured a long RNA helix emerging from RT cleft near the RNase $\mathrm{H}$ domain as an extension of the PBS helix. Based on this result, we proposed that additional base pairs form between the vRNA and tRNA, extending the PBS helix, and that the tRNA itself refolds to form a contiguous helix. This secondary structure model differs from the past models that identified a multistem structure for the tRNA. The RTIC structure also contained density for vRNA H1, H2, and the connecting loops. The two vRNA helices are located directly above the RT polymerase active site, highlighting their proposed function as a structural barrier to initiation. $\mathrm{H} 1$ and the connecting loop appear to position $\mathrm{H} 2$ while serving as a bridge linking RNA near the two RT active sites. Notably, the $3^{\prime}$ terminus of the tRNA is displaced from the RT polymerase active site residues, possibly because of the vRNA helices acting to prevent proper translocation and accommodation after nucleotide incorporation. Capturing of this pretranslocation +1 state may explain the low processivity observed during early stages of initiation.

The structural heterogeneity observed in the EM data, which could be modeled as RNA helical movements rather than alternative folds, appears to corroborate the results from Coey et al. (2018) that observed reduced RNA dynamics upon RT binding (Fig. 4). Although local flexibility hindered our ability to resolve the detailed structure of vRNA 

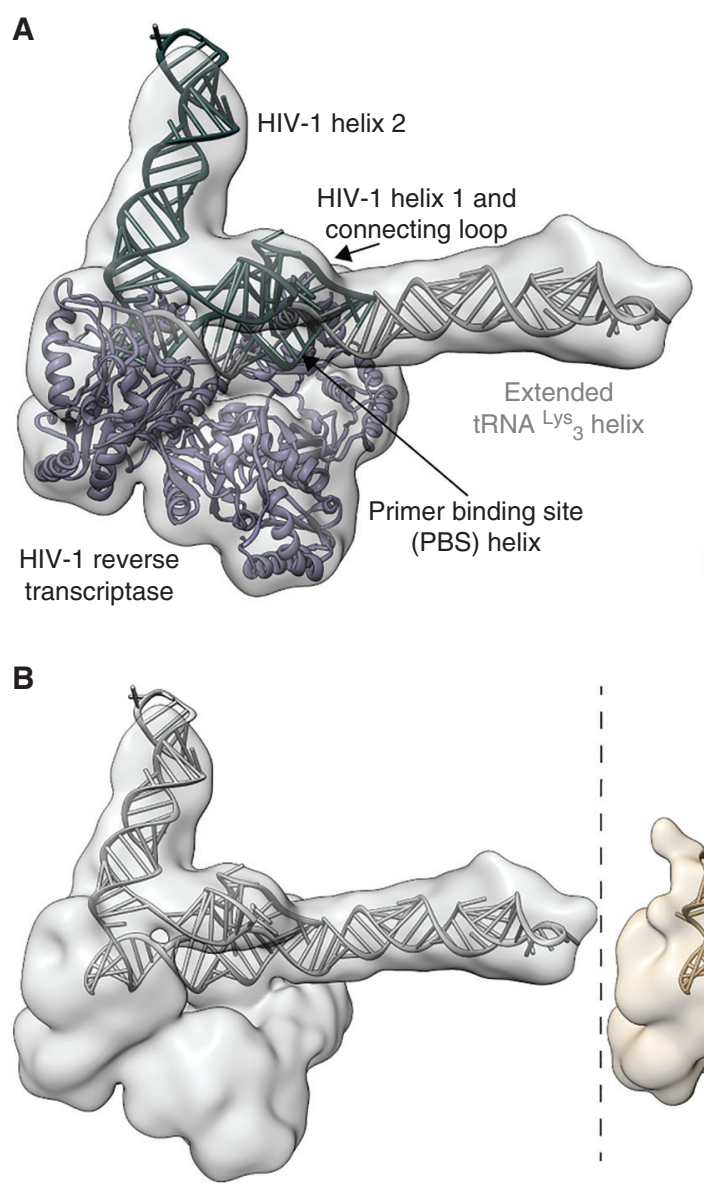

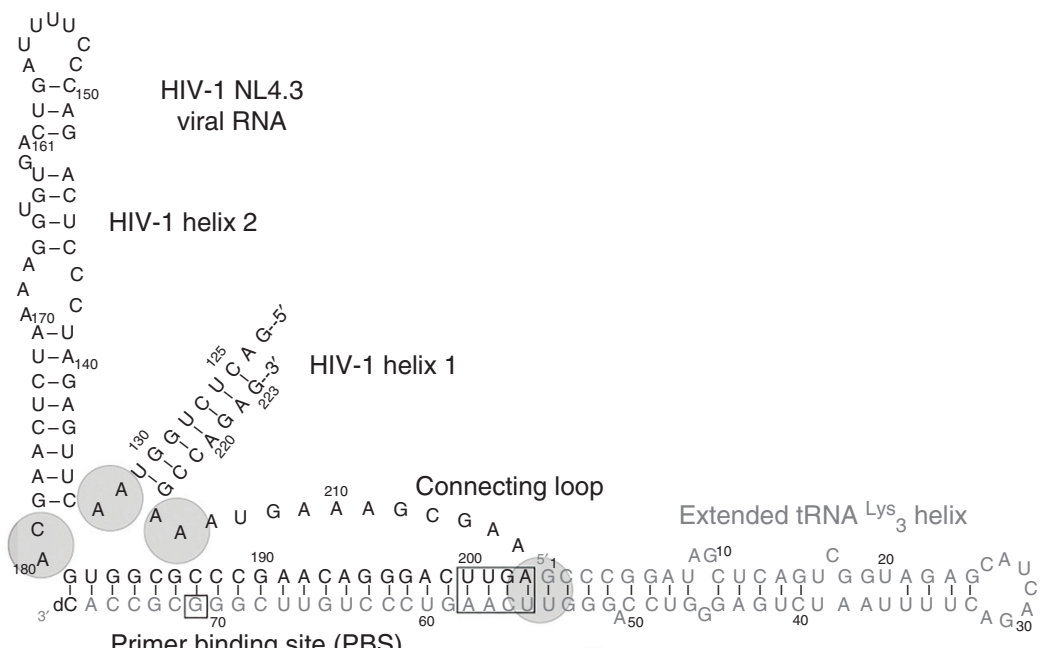

Primer binding site (PBS)
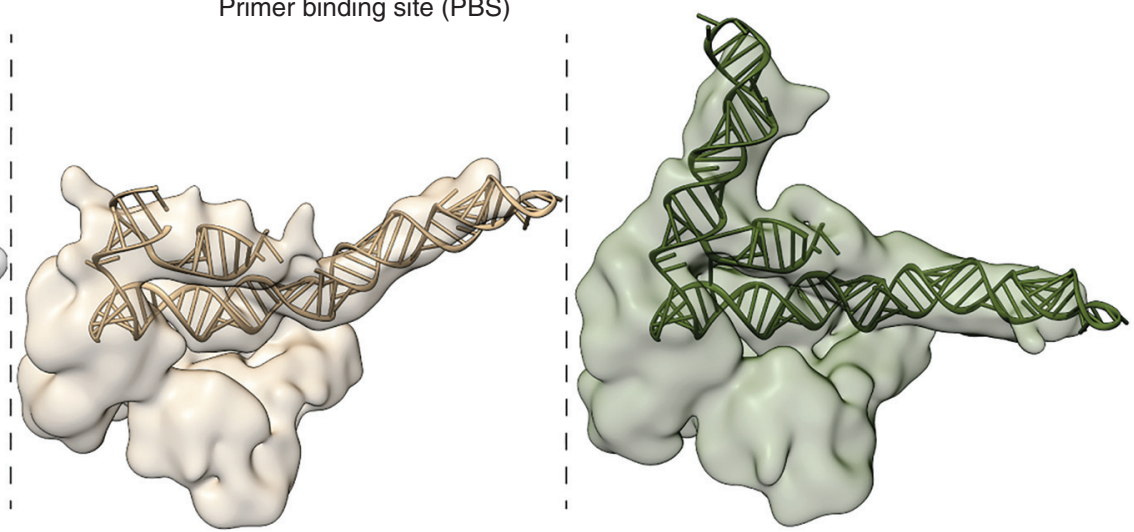

Figure 5. (A) Global tertiary and secondary structure of the RT initiation complex (RTIC) at the +1 extension state. The cryo-EM density encompasses all of vRNA H1, the PBS, and the tRNA. Density of H2 is weak near the apical end. $(B)$ Three different global cryo-EM class averages of the RTIC. Alternative RNA models were generated by treating the $\mathrm{H} 1, \mathrm{H} 2$, and extended tRNA helices as rigid bodies. The flexible junctions are indicated in $A$. The center class showed very little density for the upper stem of H2. (Data adapted from Larsen et al. 2018.)

H1, it appears to occupy a defined region of space that varies slightly among all cryo-EM classes. This agrees with the single-molecule FRET data that showed reduced $\mathrm{H} 1$ global flexibility upon RT binding. The majority of the global heterogeneity for the +1 state of the RTIC involves the orientation of the extended tRNA and the apical portion of vRNA H2 with respect to the core (Fig. 5). These regions include the tRNA anti-PAS, anticodon, and the vRNA Crich and A-rich loops. Although these domains may be flexible, they are linked together through the vRNA connecting loop and H1. Such a linkage between these RNA elements may limit their spatial orientations to allow the RNAs to refold and form intermolecular structures as reverse transcription progresses and disrupts the vRNA helices.

Although this structure of a +1 RTIC highlighted a previously unobserved vRNA-tRNA conformation and a possible explanation for the low processivity during early initiation, many questions regarding initiation remain open and higher-resolution structures are still needed. A single structure of an RNA assembly is just one snapshot of a molecular movie that links structures together through the dynamics of initiation. Single-molecule experiments, in particular smFRET, could be key in identifying the timing of the potential vRNA-tRNA structural rearrangements and revealing key intermediates that have only yet been hypothesized. The next section will focus on the next steps in studying HIV-1 reverse transcription initiation and how current methods can be harnessed to develop a more complete understanding of how the process evolves.

\section{NEXT STEPS IN STUDYING HIV-1 REVERSE TRANSCRIPTION INITIATION}

Investigation of the structure and dynamics of reverse transcription initiation has focused on discrete extension "states" (Lanchy et al. 1998; Lanchy et al. 2000; Liu et al. 
2010; Coey et al. 2018; Larsen et al. 2018). Single-molecule experiments have directly monitored the interactions of RT with the vRNA-tRNA complex, but without simultaneously monitoring the polymerase activity of RT (Liu et al. 2010; Coey et al. 2018). RNA complexes are most frequently left unextended or preextended with a combination of deoxynucleotides and dideoxynucleotides to prevent further extension. Population changes can be monitored after adding an incoming nucleotide, which partially mimics extension via nucleotide binding. However, such experiments still rely on preextended primer-template complexes that may have already undergone conformational changes following incorporation. Real-time experiments, similar to those described above for translation, are needed.

All of the proposed vRNA-tRNA structural rearrangements have yet to be directly observed during the actual process of initiation. FRET-labeling schemes designed to monitor the formation these vRNA-tRNA structures revealed the PAS interaction in a simplified system, but these have yet to be combined with RT binding and extension. The ability to perform real-time RT extension assays using labeled nucleotides as seen in Vilfan et al. (2013), while simultaneously monitoring helix formation and destabilization, could be explored. Initiation has been described as a highly dissociative process, with weak affinity of RT for the vRNA-tRNA complex. Therefore, applying single-molecule methods in a manner that can correlate productive RT binding with RNA rearrangements will alleviate many mysteries surrounding the steps that govern initiation.

The structural heterogeneity observed in +1 RTIC data suggests that the RNA elements remain highly dynamic even in the absence of complete structural rearrangements (Larsen et al. 2018). Even with large data sets, the resolution of such conformers will likely be limited by multiple global and local RNA conformations. Designing singlemolecule FRET experiments to probe the distances between RNA domains may serve as a vital tool to aid in more accurately applying molecular modeling tools like Rosetta (Das et al. 2010). The emergence of time-resolved and temperature-dependent (freezing after incubation at different temperatures) cryo-EM is appealing to the study of such a dynamic process (Zhang et al. 2013; Frank 2017a; Kaledhonkar et al. 2018). However, limitations in sample preparation for structural studies remain. The high dissociation rate of RT for the vRNA-tRNA complex limited our current structure approach to a cross-linking method, which traps extension states and would prevent any timeresolved studies (Huang et al. 1998; Huang et al. 2000; Larsen et al. 2018). Whereas such methodology will likely allow for solving the structures of additional RTIC states, single-molecule methods will aid in linking the transient structural snapshots.

\section{CONCLUDING REMARKS}

This is a wonderful moment for combined dynamic and structural studies of RNAs and their complexes. The explosion of structural methods, in particular cryo-EM with its acute ability to define conformational states, combined with powerful single-molecule dynamics approaches, has driven progress in creating molecular movies. The results presented here on translation and reverse transcription highlight the importance of detailed structural information by either cryo-EM or X-ray methods to form functional hypotheses. NMR and single-molecule methods allowed us to delineate and measure conformational dynamics in these systems, and computational approaches underpinned all our efforts. The results show the local and global plasticity of RNA, and how minor perturbations in structure or dynamics can lead to large functional consequences.

Moving forward, technological advances will improve structural resolution, power computational methods, and improve temporal resolution of dynamics experiments. The result will be a more holistic view of how RNAs and their assemblies rearrange during the delicate dance of their function.

\section{ACKNOWLEDGMENTS}

Single-molecule translation research in the Puglisi group is supported by the National Institutes of Health (NIH) grants GM51266, GM113078, AI047365, AI099506 to J.D.P. HIV1 reverse transcription research is supported by NIH Grant GM082545 to E.V.P., K.P.L., and A.P. are funded by NIH Molecular Biophysics Training Grant (T32-GM008294). J.C. and A.P. are funded by the Stanford Interdisciplinary Graduate Fellowship (Bio-X). We thank H. Demirci for helping with the figure preparation.

\section{REFERENCES}

${ }^{*}$ Reference is also in this collection.

Aitken CE, Puglisi JD. 2010. Following the intersubunit conformation of the ribosome during translation in real time. Nat Struct Mol Biol 17: 793-800.

Al-Hashimi HM. 2013. NMR studies of nucleic acid dynamics. J Magn Reson 237: 191-204.

Bai XC, McMullan G, Scheres SH. 2015. How cryo-EM is revolutionizing structural biology. Trends Biochem Sci 40: 49-57.

Baltimore D. 1970. RNA-dependent DNA polymerase in virions of RNA tumour viruses. Nature 226: 1209-1211.

Bashan A, Yonath A. 2008. Correlating ribosome function with highresolution structures. Trends Microbiol 16: 326-335.

Beerens N, Berkhout B. 2002a. Switching the in vitro tRNA usage of HIV1 by simultaneous adaptation of the PBS and PAS. RNA 8: 357-369.

Beerens N, Berkhout B. 2002b. The tRNA primer activation signal in the human immunodeficiency virus type 1 genome is important for initiation and processive elongation of reverse transcription. J Virol 76: 2329-2339. 
Beerens N, Groot F, Berkhout B. 2001. Initiation of HIV-1 reverse transcription is regulated by a primer activation signal. J Biol Chem 276: 31247-31256.

Beerens N, Jepsen MD, Nechyporuk-Zloy V, Kruger AC, Darlix JL, Kjems J, Birkedal V. 2013. Role of the primer activation signal in tRNA annealing onto the HIV-1 genome studied by single-molecule FRET microscopy. RNA 19: 517-526.

Bilbille Y, Vendeix FA, Guenther R, Malkiewicz A, Ariza X, Vilarrasa J, Agris PF. 2009. The structure of the human tRNA ${ }_{3}^{\text {Lys }}$ anticodon bound to the HIV genome is stabilized by modified nucleosides and adjacent mismatch base pairs. Nucleic Acids Res 37: 3342-3353.

Blanchard SC, Gonzalez RL, Kim HD, Chu S, Puglisi JD. 2004. tRNA selection and kinetic proofreading in translation. Nat Struct Mol Biol 11: 1008-1014.

Boccaletto P, Machnicka MA, Purta E, Piatkowski P, Baginski B, Wirecki TK, de Crecy-Lagard V, Ross R, Limbach PA, Kotter A, et al. 2018. MODOMICS: A database of RNA modification pathways. 2017 update. Nucleic Acids Res 46: D303-D307.

Chapman HN, Fromme P, Barty A, White TA, Kirian RA, Aquila A, Hunter MS, Schulz J, DePonte DP, Weierstall U, et al. 2011. Femtosecond X-ray protein nanocrystallography. Nature 470: 73-77.

Chen B, Kaledhonkar S, Sun M, Shen B, Lu Z, Barnard D, Lu TM, Gonzalez RL Jr., Frank J. 2015. Structural dynamics of ribosome subunit association studied by mixing-spraying time-resolved cryogenic electron microscopy. Structure 23: 1097-1105.

Cheng Y. 2015. Single-particle cryo-EM at crystallographic resolution. Cell 161: 450-457.

Cheng CY, Chou FC, Das R. 2015. Modeling complex RNA tertiary folds with Rosetta. Methods Enzymol 553: 35-64.

Choi J, Ieong K-W, Demirci H, Chen J, Petrov A, Prabhakar A, O'Leary SE, Dominissini D, Rechavi G, Soltis SM, et al. 2016. N6-methyladenosine in mRNA disrupts tRNA selection and translation-elongation dynamics. Nat Struct Mol Biol 23: 110-115.

Choi J, Indrisiunaite G, DeMirci H, Ieong K-W, Wang J, Petrov A, Prabhakar A, Rechavi G, Dominissini D, He C, et al. 2018. 2'-O-methylation in mRNA disrupts tRNA decoding during translation elongation. Nat Struct Mol Biol 25: 208-216.

Coey A, Larsen K, Puglisi JD, Viani Puglisi E. 2016. Heterogeneous structures formed by conserved RNA sequences within the HIV reverse transcription initiation site. RNA 22: 1689-1698.

Coey A, Larsen KP, Barrero D, Puglisi JD, Puglisi EV. 2018. Dynamic interplay of RNA and protein in the human immunodeficiency virus-1 reverse transcription initiation complex. J Mol Biol (in press).

Cummins LL, Owens SR, Risen LM, Lesnik EA, Freier SM, McGee D, Guinosso CJ, Cook PD. 1995. Characterization of fully $2^{\prime}$-modified oligoribonucleotide hetero- and homoduplex hybridization and nuclease sensitivity. Nucleic Acids Res 23: 2019-2024.

Dai Q, Moshitch-Moshkovitz S, Han D, Kol N, Amariglio N, Rechavi G, Dominissini D, He C. 2017. Nm-seq maps 2'-O-methylation sites in human mRNA with base precision. Nat Methods 14: 695-698.

Das R, Karanicolas J, Baker D. 2010. Atomic accuracy in predicting and designing noncanonical RNA structure. Nat Methods 7: 291-294.

Das K, Martinez SE, Bauman JD, Arnold E. 2012. HIV-1 reverse transcriptase complex with DNA and nevirapine reveals non-nucleoside inhibition mechanism. Nat Struct Mol Biol 19: 253-259.

Das K, Martinez SE, Bandwar RP, Arnold E. 2014. Structures of HIV-1 RT-RNA/DNA ternary complexes with dATP and nevirapine reveal conformational flexibility of RNA/DNA: Insights into requirements for RNase H cleavage. Nucleic Acids Res 42: 8125-8137.

Dominissini D, Moshitch-Moshkovitz S, Schwartz S, Salmon-Divon M, Ungar L, Osenberg S, Cesarkas K, Jacob-Hirsch J, Amariglio N, Kupiec $\mathrm{M}$, et al. 2012. Topology of the human and mouse m6A RNA methylomes revealed by m6A-seq. Nature 485: 201-206.

Dorywalska M, Blanchard SC, Gonzalez RL, Kim HD, Chu S, Puglisi JD. 2005. Site-specific labeling of the ribosome for single-molecule spectroscopy. Nucleic Acids Res 33: 182-189.
Fernandez IS, Ng CL, Kelley AC, Wu G, Yu YT, Ramakrishnan V. 2013. Unusual base pairing during the decoding of a stop codon by the ribosome. Nature 500: 107-110.

Fourmy D, Yoshizawa S, Puglisi JD. 1998. Paromomycin binding induces a local conformational change in the A-site of $16 \mathrm{~S}$ rRNA. J Mol Biol 277: 333-345.

Frank J. 2017a. Time-resolved cryo-electron microscopy: Recent progress. J Struct Biol 200: 303-306.

Frank J. 2017b. The translation elongation cycle-Capturing multiple states by cryo-electron microscopy. Philos Trans R Soc B Biol Sci 372: 20160180.

Frank J, Agrawal RK. 2000. A ratchet-like inter-subunit reorganization of the ribosome during translocation. Nature 406: 318-322.

Friedman LJ, Gelles J. 2015. Multi-wavelength single-molecule fluorescence analysis of transcription mechanisms. Methods 86: 27-36.

Fu Z, Kaledhonkar S, Borg A, Sun M, Chen B, Grassucci RA, Ehrenberg M, Frank J. 2016. Key intermediates in ribosome recycling visualized by time-resolved cryoelectron microscopy. Structure 24: 2092-2101.

Gilboa E, Mitra SW, Goff S, Baltimore D. 1979. A detailed model of reverse transcription and tests of crucial aspects. Cell 18: 93-100.

Goldschmidt V, Rigourd M, Ehresmann C, Le Grice SF, Ehresmann B, Marquet R. 2002. Direct and indirect contributions of RNA secondary structure elements to the initiation of HIV-1 reverse transcription. J Biol Chem 277: 43233-43242.

Goldschmidt V, Ehresmann C, Ehresmann B, Marquet R. 2003. Does the HIV-1 primer activation signal interact with $\mathrm{tRNA}^{\mathrm{Lys}}{ }_{3}$ during the initiation of reverse transcription? Nucleic Acids Res 31: 850-859.

Goldschmidt V, Paillart JC, Rigourd M, Ehresmann B, Aubertin AM, Ehresmann C, Marquet R. 2004. Structural variability of the initiation complex of HIV-1 reverse transcription. J Biol Chem 279: 35923-35931.

Gorini L. 1971. Ribosomal discrimination of tRNAs. Nat New Biol 234: 261-264.

He C. 2010. Grand challenge commentary: RNA epigenetics? Nat Chem Biol 6: 863-865.

Hopfield JJ. 1974. Kinetic proofreading: A new mechanism for reducing errors in biosynthetic processes requiring high specificity. Proc Natl Acad Sci 71: 4135-4139.

Hoskins AA, Gelles J, Moore MJ. 2011. New insights into the spliceosome by single molecule fluorescence microscopy. Curr Opin Chem Biol 15: 864-870.

Hu WS, Hughes SH. 2012. HIV-1 reverse transcription. Cold Spring Harb Perspect Med 2: a006882.

Huang H, Chopra R, Verdine GL, Harrison SC. 1998. Structure of a covalently trapped catalytic complex of HIV-1 reverse transcriptase: Implications for drug resistance. Science 282: 1669-1675.

Huang H, Harrison SC, Verdine GL. 2000. Trapping of a catalytic HIV reverse transcriptase*template:primer complex through a disulfide bond. Chem Biol 7: 355-364.

Isel C, Marquet R, Keith G, Ehresmann C, Ehresmann B. 1993. Modified nucleotides of $\mathrm{TRNA}^{\mathrm{Lys}}{ }_{3}$ modulate primer/template loop-loop interaction in the initiation complex of HIV-1 reverse transcription. J Biol Chem 268: 25269-25272.

Isel C, Ehresmann C, Keith G, Ehresmann B, Marquet R. 1995. Initiation of reverse transcription of HIV-1: Secondary structure of the HIV-1 RNA/tRNA ${ }_{3}^{\text {Lys }}$ (template/primer). J Mol Biol 247: 236-250.

Isel C, Lanchy JM, Le Grice SF, Ehresmann C, Ehresmann B, Marquet R. 1996. Specific initiation and switch to elongation of human immunodeficiency virus type 1 reverse transcription require the post-transcriptional modifications of primer tRNA ${ }_{3}^{\text {Lys }}$. EMBO J 15: 917-924.

Isel C, Keith G, Ehresmann B, Ehresmann C, Marquet R. 1998. Mutational analysis of the tRNA ${ }_{3}^{\text {Lys }}{ }_{3} / \mathrm{HIV}-1$ RNA (primer/template) complex. Nucleic Acids Res 26: 1198-1204.

Isel C, Westhof E, Massire C, Le Grice SF, Ehresmann B, Ehresmann C, Marquet R. 1999. Structural basis for the specificity of the initiation of HIV-1 reverse transcription. EMBO J 18: 1038-1048.

Isel C, Ehresmann C, Marquet R. 2010. Initiation of HIV reverse transcription. Viruses 2: 213-243. 
Iwatani Y, Rosen AE, Guo J, Musier-Forsyth K, Levin JG. 2003. Efficient initiation of HIV-1 reverse transcription in vitro. Requirement for RNA sequences downstream of the primer binding site abrogated by nucleocapsid protein-dependent primer-template interactions. J Biol Chem 278: 14185-14195.

Johansson M, Zhang J, Ehrenberg M. 2012. Genetic code translation displays a linear trade-off between efficiency and accuracy of tRNA selection. Proc Natl Acad Sci 109: 131-136.

Jung YO, Lee JH, Kim J, Schmidt M, Moffat K, Srajer V, Ihee H. 2013. Volume-conserving trans-cis isomerization pathways in photoactive yellow protein visualized by picosecond X-ray crystallography. Nat Chem 5: 212-220.

Kaledhonkar S, Fu Z, White H, Frank J. 2018. Time-resolved cryo-electron microscopy using a microfluidic chip. Methods Mol Biol 1764: 59-71.

Karijolich J, Yu YT. 2011. Converting nonsense codons into sense codons by targeted pseudouridylation. Nature 474: 395-398.

Kati WM, Johnson KA, Jerva LF, Anderson KS. 1992. Mechanism and fidelity of HIV reverse transcriptase. J Biol Chem 267: 2598825997.

Kraynack BA. 2006. Small interfering RNAs containing full 2'-O-methylribonucleotide-modified sense strands display Argonaute2/eIF2C2dependent activity. RNA 12: 163-176.

Lanchy JM, Ehresmann C, Le Grice SF, Ehresmann B, Marquet R. 1996. Binding and kinetic properties of HIV-1 reverse transcriptase markedly differ during initiation and elongation of reverse transcription. EMBO J 15: 7178-7187.

Lanchy JM, Keith G, Le Grice SF, Ehresmann B, Ehresmann C, Marquet R. 1998. Contacts between reverse transcriptase and the primer strand govern the transition from initiation to elongation of HIV-1 reverse transcription. J Biol Chem 273: 24425-24432.

Lanchy JM, Isel C, Keith G, Le Grice SF, Ehresmann C, Ehresmann B, Marquet R. 2000. Dynamics of the HIV-1 reverse transcription complex during initiation of DNA synthesis. J Biol Chem 275: 12306-12312.

Larsen KP, Mathiharan YK, Kappel K, Coey AT, Chen D-H, Barrero D, Madigan L, Puglisi JD, Skiniotis G, Puglisi EV. 2018. Architecture of an HIV-1 reverse transcriptase initiation complex. Nature 557: 118122.

Levene MJ, Korlach J, Turner SW, Foquet M, Craighead HG, Webb WW. 2003. Zero-mode waveguides for single-molecule analysis at high concentrations. Science 299: 682-686.

Li X, Mooney P, Zheng S, Booth CR, Braunfeld MB, Gubbens S, Agard DA, Cheng Y. 2013. Electron counting and beam-induced motion correction enable near-atomic-resolution single-particle cryo-EM. Nat Methods 10: 584-590.

Li A, Gong S, Johnson KA. 2016. Rate-limiting pyrophosphate release by HIV reverse transcriptase improves fidelity. J Biol Chem 291: 2655426565.

Liang C, Li X, Rong L, Inouye P, Quan Y, Kleiman L, Wainberg MA. 1997. The importance of the A-rich loop in human immunodeficiency virus type 1 reverse transcription and infectivity. J Virol 71: 5750-5757.

Liang C, Rong L, Gotte M, Li X, Quan Y, Kleiman L, Wainberg MA. 1998. Mechanistic studies of early pausing events during initiation of HIV-1 reverse transcription. J Biol Chem 273: 21309-21315.

* Linder B, Jaffrey SR. 2019. Discovering and mapping the modified nucleotides that comprise the epitranscriptome of mRNA. Cold Spring Harb Perspect Biol doi: 10.1101/cshperspect.a032201.

Liu S, Harada BT, Miller JT, Le Grice SF, Zhuang X. 2010. Initiation complex dynamics direct the transitions between distinct phases of early HIV reverse transcription. Nat Struct Mol Biol 17: 1453-1460.

Los GV, Encell LP, McDougall MG, Hartzell DD, Karassina N, Zimprich C, Wood MG, Learish R, Ohana RF, Urh M, et al. 2008. HaloTag: A novel protein labeling technology for cell imaging and protein analysis. ACS Chem Biol 3: 373-382.

Marko RA, Liu HW, Ablenas CJ, Ehteshami M, Gotte M, Cosa G. 2013. Binding kinetics and affinities of heterodimeric versus homodimeric HIV-1 reverse transcriptase on DNA-DNA substrates at the singlemolecule level. J Phys Chem B 117: 4560-4567.
Meyer KD, Saletore Y, Zumbo P, Elemento O, Mason Christopher E, Jaffrey Samie R. 2012. Comprehensive analysis of mRNA methylation reveals enrichment in 3' UTRs and near stop codons. Cell 149: 16351646.

Moazed D, Noller HF. 1989. Intermediate states in the movement of transfer RNA in the ribosome. Nature 342: 142-148.

Mollwitz B, Brunk E, Schmitt S, Pojer F, Bannwarth M, Schiltz M, Rothlisberger U, Johnsson K. 2012. Directed evolution of the suicide protein $\mathrm{O}^{6}$-alkylguanine-DNA alkyltransferase for increased reactivity results in an alkylated protein with exceptional stability. Biochemistry 51: 986994.

Ninio J. 1975. Kinetic amplification of enzyme discrimination. Biochimie 57: 587-595.

Ogle JM, Brodersen DE, Clemons WM Jr., Tarry MJ, Carter AP, Ramakrishnan V. 2001. Recognition of cognate transfer RNA by the $30 \mathrm{~S}$ ribosomal subunit. Science 292: 897-902.

Ogle JM, Murphy FV, Tarry MJ, Ramakrishnan V. 2002. Selection of tRNA by the ribosome requires a transition from an open to a closed form. Cell 111: 721-732.

Ooms M, Cupac D, Abbink TE, Huthoff H, Berkhout B. 2007. The availability of the primer activation signal (PAS) affects the efficiency of HIV-1 reverse transcription initiation. Nucleic Acids Res 35: 16491659.

Paillart JC, Dettenhofer M, Yu XF, Ehresmann C, Ehresmann B, Marquet R. 2004. First snapshots of the HIV-1 RNA structure in infected cells and in virions. J Biol Chem 279: 48397-48403.

Prabhakar A, Capece MC, Petrov A, Choi J, Puglisi JD. 2017. Post-termination ribosome intermediate acts as the gateway to ribosome recycling. Cell Rep 20: 161-172.

Puglisi EV, Puglisi JD. 1998. HIV-1 A-rich RNA loop mimics the tRNA anticodon structure. Nat Struct Biol 5: 1033-1036.

Puglisi EV, Puglisi JD. 2011. Secondary structure of the HIV reverse transcription initiation complex by NMR. J Mol Biol 410: 863-874.

Ratner L, Haseltine W, Patarca R, Livak KJ, Starcich B, Josephs SF, Doran ER, Rafalski JA, Whitehorn EA, Baumeister K, et al. 1985. Complete nucleotide sequence of the AIDS virus, HTLV-III. Nature 313: 277284.

Reuter JS, Mathews DH. 2010. RNAstructure: Software for RNA secondary structure prediction and analysis. BMC Bioinformatics 11: 129.

Robinson PJ, Trnka MJ, Bushnell DA, Davis RE, Mattei PJ, Burlingame AL, Kornberg RD. 2016. Structure of a complete mediator-RNA polymerase II pre-initiation complex. Cell 166: 1411-1422.e16.

Roost C, Lynch SR, Batista PJ, Qu K, Chang HY, Kool ET. 2015. Structure and thermodynamics of $N^{6}$-methyladenosine in RNA: A spring-loaded base modification. J Am Chem Soc 137: 2107-2115.

Roundtree IA, Evans ME, Pan T, He C. 2017. Dynamic RNA modifications in gene expression regulation. Cell 169: 1187-1200.

Saletore Y, Meyer K, Korlach J, Vilfan ID, Jaffrey S, Mason CE. 2012. The birth of the Epitranscriptome: Deciphering the function of RNA modifications. Genome Biol 13: 175.

Sarafianos SG, Das K, Tantillo C, Clark AD Jr., Ding J, Whitcomb JM, Boyer PL, Hughes SH, Arnold E. 2001. Crystal structure of HIV-1 reverse transcriptase in complex with a polypurine tract RNA:DNA. EMBO J 20: 1449-1461.

Sarafianos SG, Marchand B, Das K, Himmel DM, Parniak MA, Hughes SH, Arnold E. 2009. Structure and function of HIV-1 reverse transcriptase: Molecular mechanisms of polymerization and inhibition. $J \mathrm{Mol}$ Biol 385: 693-713.

Simonović M, Steitz TA. 2009. A structural view on the mechanism of the ribosome-catalyzed peptide bond formation. Biochim Biophys Acta 1789: 612-623.

Srajer V, Teng T, Ursby T, Pradervand C, Ren Z, Adachi S, Schildkamp W, Bourgeois D, Wulff M, Moffat K. 1996. Photolysis of the carbon monoxide complex of myoglobin: Nanosecond time-resolved crystallography. Science 274: 1726-1729. 
Stagno JR, Bhandari YR, Conrad CE, Liu Y, Wang YX. 2017. Real-time crystallographic studies of the adenine riboswitch using an X-ray freeelectron laser. FEBS J 284: 3374-3380.

Suo Z, Johnson KA. 1997a. Effect of RNA secondary structure on the kinetics of DNA synthesis catalyzed by HIV-1 reverse transcriptase. Biochemistry 36: 12459-12467.

Suo Z, Johnson KA. 1997b. RNA secondary structure switching during DNA synthesis catalyzed by HIV-1 reverse transcriptase. Biochemistry 36: $14778-14785$.

Temin HM, Mizutani S. 1970. RNA-dependent DNA polymerase in virions of Rous sarcoma virus. Nature 226: 1211-1213.

Tenboer J, Basu S, Zatsepin N, Pande K, Milathianaki D, Frank M, Hunter M, Boutet S, Williams GJ, Koglin JE, et al. 2014. Time-resolved serial crystallography captures high-resolution intermediates of photoactive yellow protein. Science 346: 1242-1246.

Uemura S, Aitken CE, Korlach J, Flusberg BA, Turner SW, Puglisi JD. 2010. Real-time tRNA transit on single translating ribosomes at codon resolution. Nature 464: 1012-1017.

Vaccaro JA, Singh HA, Anderson KS. 1999. Initiation of minus-strand DNA synthesis by human immunodeficiency virus type 1 reverse transcriptase. Biochemistry 38: 15978-15985.

Vilfan ID, Tsai YC, Clark TA, Wegener J, Dai Q, Yi C, Pan T, Turner SW, Korlach J. 2013. Analysis of RNA base modification and structural rearrangement by single-molecule real-time detection of reverse transcription. J Nanobiotechnol 11: 8.

Voorhees RM, Ramakrishnan V. 2013. Structural basis of the translational elongation cycle. Ann Rev Biochem 82: 203-236.
Wasserman MR, Alejo JL, Altman RB, Blanchard SC. 2016. Multiperspective smFRET reveals rate-determining late intermediates of ribosomal translocation. Nat Struct Mol Biol 23: 333-341.

Yan C, Hang J, Wan R, Huang M, Wong CC, Shi Y. 2015. Structure of a yeast spliceosome at 3.6-angstrom resolution. Science 349: 11821191.

Yin J, Straight PD, McLoughlin SM, Zhou Z, Lin AJ, Golan DE, Kelleher NL, Kolter R, Walsh CT. 2005. Genetically encoded short peptide tag for versatile protein labeling by Sfp phosphopantetheinyl transferase. Proc Natl Acad Sci 102: 15815-15820.

Yoshizawa S. 1999. Recognition of the codon-anticodon helix by ribosomal RNA. Science 285: 1722-1725.

Yusupova G, Yusupov M. 2017. Crystal structure of eukaryotic ribosome and its complexes with inhibitors. Philos Trans R Soc B Biol Sci 372: 20160184.

Zaher HS, Green R. 2009. Quality control by the ribosome following peptide bond formation. Nature 457: 161-166.

Zhang X, Sheng J, Plevka P, Kuhn RJ, Diamond MS, Rossmann MG. 2013. Dengue structure differs at the temperatures of its human and mosquito hosts. Proc Natl Acad Sci 110: 6795-6799.

Zhou H, Kimsey IJ, Nikolova EN, Sathyamoorthy B, Grazioli G, McSally J, Bai T, Wunderlich CH, Kreutz C, Andricioaei I, et al. 2016. $\mathrm{m}(1) \mathrm{A}$ and $\mathrm{m}(1) \mathrm{G}$ disrupt A-RNA structure through the intrinsic instability of Hoogsteen base pairs. Nat Struct Mol Biol 23: 803-810.

Zuker M. 2003. Mfold web server for nucleic acid folding and hybridization prediction. Nucleic Acids Res 31: 3406-3415. 


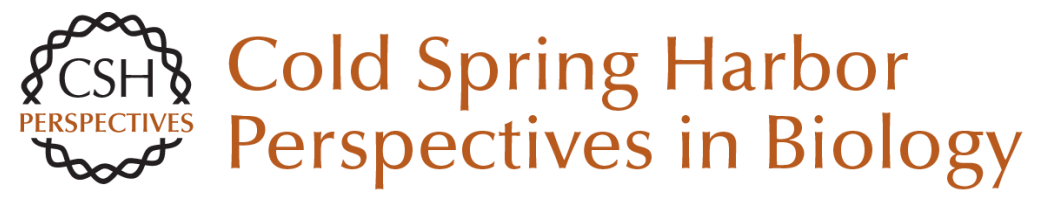

\section{Relating Structure and Dynamics in RNA Biology}

Kevin P. Larsen, Junhong Choi, Arjun Prabhakar, Elisabetta Viani Puglisi and Joseph D. Puglisi

Cold Spring Harb Perspect Biol 2019; doi: 10.1101/cshperspect.a032474

Subject Collection RNA Worlds

Alternate RNA Structures

Marie Teng-Pei Wu and Victoria D'Souza

Approaches for Understanding the Mechanisms

of Long Noncoding RNA Regulation of Gene

Expression

Patrick McDonel and Mitchell Guttman

Principles and Practices of Hybridization Capture

Experiments to Study Long Noncoding RNAs That

Act on Chromatin

Matthew D. Simon and Martin Machyna

Linking RNA Sequence, Structure, and Function

on Massively Parallel High-Throughput

Sequencers

Sarah K. Denny and William J. Greenleaf

Extensions, Extra Factors, and Extreme

Complexity: Ribosomal Structures Provide

Insights into Eukaryotic Translation

Melanie Weisser and Nenad Ban

Nascent RNA and the Coordination of Splicing with Transcription

Karla M. Neugebauer

Combining Mass Spectrometry (MS) and Nuclear Magnetic Resonance (NMR) Spectroscopy for Integrative Structural Biology of Protein-RNA Complexes

Alexander Leitner, Georg Dorn and Frédéric H.-T. Allain
Structural Biology of Telomerase

Yaqiang Wang, Lukas Susac and Juli Feigon

Structural Insights into Nuclear pre-mRNA

Splicing in Higher Eukaryotes

Berthold Kastner, Cindy L. Will, Holger Stark, et al.

What Are 3' UTRs Doing?

Christine Mayr

Single-Molecule Analysis of Reverse

Transcriptase Enzymes

Linnea I. Jansson and Michael D. Stone

CRISPR Tools for Systematic Studies of RNA

Regulation

Jesse Engreitz, Omar Abudayyeh, Jonathan

Gootenberg, et al.

Relating Structure and Dynamics in RNA Biology Kevin P. Larsen, Junhong Choi, Arjun Prabhakar, et al.

Beyond DNA and RNA: The Expanding Toolbox of Synthetic Genetics

Alexander I. Taylor, Gillian Houlihan and Philipp Holliger

For additional articles in this collection, see http://cshperspectives.cshlp.org/cgi/collection/

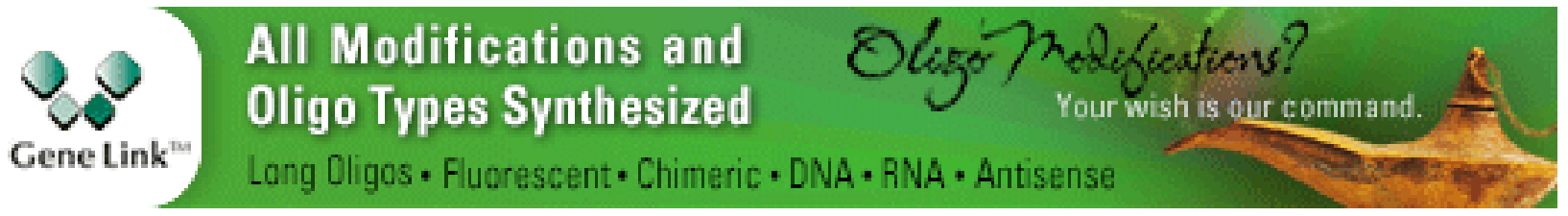

Copyright @ 2019 Cold Spring Harbor Laboratory Press; all rights reserved 
Discovering and Mapping the Modified Nucleotides That Comprise the Epitranscriptome of mRNA

Bastian Linder and Samie R. Jaffrey
Structural Basis of Nuclear pre-mRNA Splicing:

\section{Lessons from Yeast}

Clemens Plaschka, Andrew J. Newman and Kiyoshi Nagai

For additional articles in this collection, see http://cshperspectives.cshlp.org/cgi/collection/

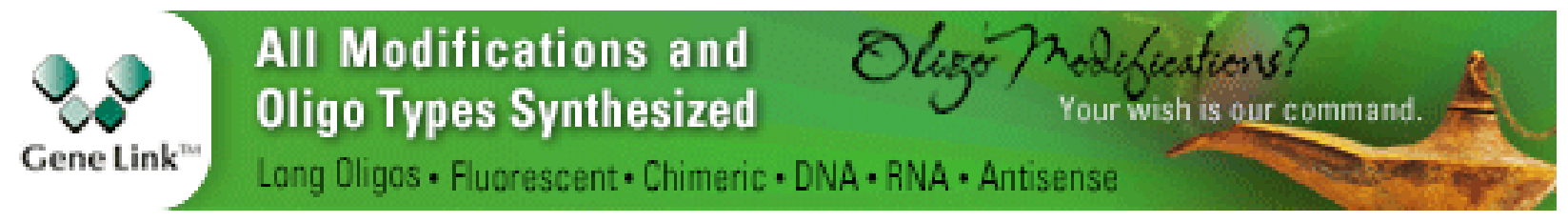

Copyright (C) 2019 Cold Spring Harbor Laboratory Press; all rights reserved 